\section{Estratigrafía, evolución estructural y restauración. El caso de la iglesia de Santa Eulalia en Marquínez (Álava)}

\section{Stratigraphy, structural evolution and restoration. The church of Santa Eulalia in Marquínez (Álava)}

\author{
Leandro Cámara*
}

Arquitecto

\begin{abstract}
Resumen
Se presenta un caso de evaluación de la estabilidad de una iglesia abovedada que toma el análisis arqueológico como principal referencia de contraste de los resultados del estudio estructural. La consideración de los edificios históricos como entidades temporales en las que se combinan la acción degradante de la naturaleza y la conservadora del hombre confiere al análisis de su seguridad estructural una mejor perspectiva que la presupuesta en los más convencionales análisis basados exclusivamente en las teorías estructurales generales y demuestra que un mejor conocimiento del comportamiento de la estructura a lo largo del tiempo debe conducir a un mayor respeto de su integridad material y a un abierto rechazo de las restauraciones más intervencionistas justificadas sólo por esos estudios estructurales. Se hace una breve revisión de la teoría de estados límite y su aplicación a las estructuras de fábrica y a la iglesia de Santa Eulalia de Marquínez en particular; en paralelo se presenta el resultado del estudio histórico de su evolución constructiva; y se conjugan las conclusiones de ambos análisis en una secuencia temporal de la evolución estructural, una revisión de su seguridad y una propuesta de intervención.
\end{abstract}

Palabras clave: análisis estructural, teoría de estados límite, diagrama estratigráfico-estructural.

\begin{abstract}
A case study of stability evaluation of a vaulted church is presented. Archaeological investigation is considered as the better contrast reference for its structural analysis results. Considering historical buildings as time objects, where degrading action of nature and conservation activity of men come together, gives to their structural safety analysis a better perspective than that one resulting from the most conventional studies exclusively based in general structural theories, and shows that a deeper knowledge of their structural behaviour throughout the time takes us to a greater respect of their material integrity and to a clear reject of the most interventionist restorations only justified by those structural analysis. It is presented a brief revision of the limit states theory and its application to masonry buildings and particularly to Santa Eulalia's church in Marquinez; simultaneously the results of the historical studies are shown; and the conclusions of both analysis are combined in a diagram of the structural behaviour evolution throughout the time, a global safety evaluation and an intervention proposal.
\end{abstract}

Keywords: structural analysis, limit states theory, stratigraphicstructural diagram.

\section{EL ANÁLISIS DE LAS ESTRUCTURAS DE FÁBRICA}

Es demasiado habitual enfrentarse al análisis de una estructura de fábrica con teorías estructurales fundadas en la resistencia de los materiales en las que se introduce como valor de cálculo un supuesto comportamiento anómalo de estas construcciones basado en su casi nula capacidad resistente a los esfuerzos de tracción, teorías con las que se generan modelos matemáticos que resultan ser muy poco adecuados a la realidad del funcionamiento de esas estructuras. Si una estructura construida con acero u hormigón armado puede estudiarse con cierta fiabilidad mediante modelos basados en el comportamiento elástico de sus materiales y en su capacidad de mantener el equilibrio mediante una gran resistencia a los esfuerzos de distintos tipos, y específicamente los de tracción, provocados por el sistema de cargas y las condiciones de contorno de su situación de servicio, una estructura de fábrica, por el contrario, está construida con materiales de comportamiento no elástico y asimétrico - menor resistencia a tracción que a compresión- y no debe su eficacia a la resistencia de esos materiales sino al sistema de equilibrio de los pesos de sus distintas partes, por lo que requiere otro tipo de análisis para evaluar su seguridad.

El tipo de análisis estructural que se emplea aquí se remonta a los desarrollos de la estática gráfica realizados durante la segunda mitad del siglo XIX, momento en el que todavía se empleaba este tipo de estructuras en toda clase de construcciones, desde edificios hasta puentes o presas, y en el que ya venía siendo necesario contar con herramientas de cálculo y modelos que previeran su comportamiento y, sobre todo, avalaran su estabilidad y seguridad. Sin embargo, la difusión del empleo del acero, un material constructivo de comportamiento resistente completamente distinto y que conducía a un tipo de estructuras también diferentes, requirió el desarrollo de otro tipo de análisis basados en el comportamiento elástico y simétrico de este material y en su gran capacidad resistente, precisamente la que le permitía dar forma a construcciones muy ligeras. Así se hace hegemónica una teoría de estructuras centrada en la resistencia de los materiales frente a una teoría centrada en el equilibrio de las masas, todo ello a la vez que se pierde la tradicional construcción de estructuras de fábrica, sustituidas por las modernas de acero y hormigón armado, en general mucho más sencillas estáticamente.

${ }^{1}$ Este artículo se desprende del proyecto de Restauración Estructural de la Iglesia
de Santa Eulalia de Marquínez (Álava), redactado por Arabarri, S.A. (ver ficha técnica al final del texto). 


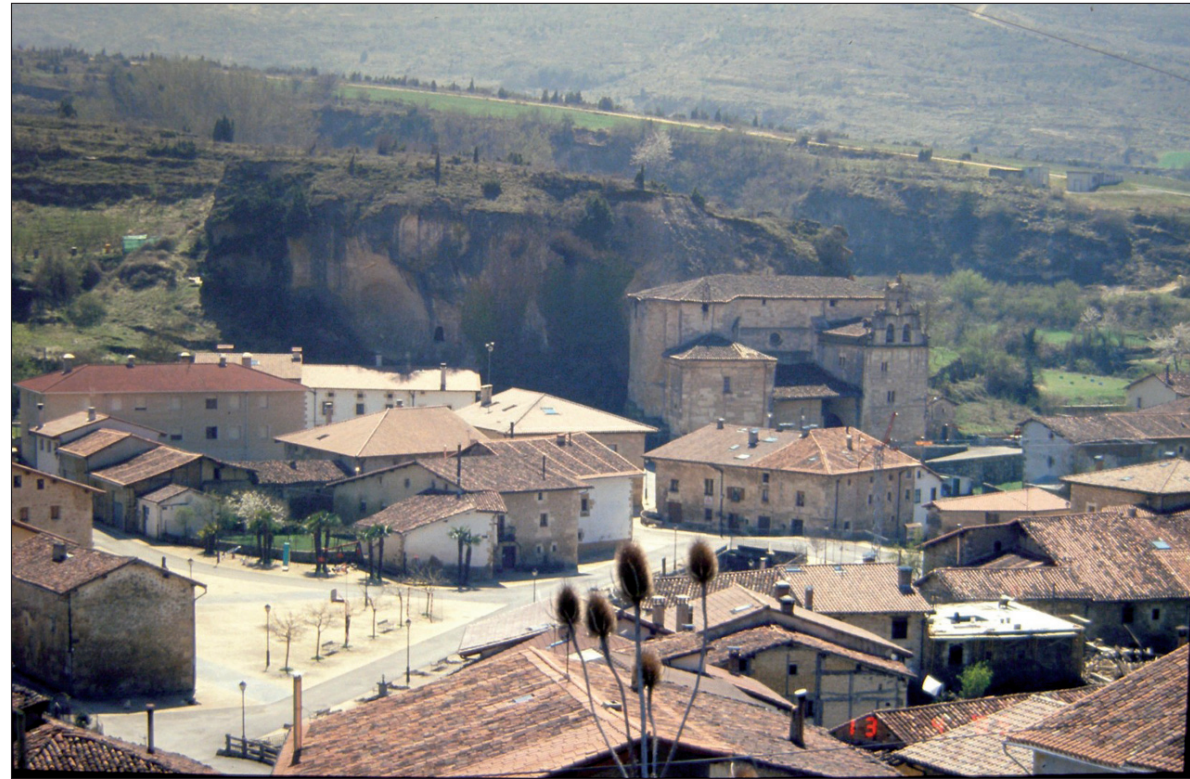

Fig. 1. Vista general del pueblo de Marquínez, con la iglesia de Santa Eulalia al fondo. Tras ella, el roquedo sobre cuyos detritus geológicos se asienta. Delante, junto a las casas más cercanas, se aprecia uno de los pequeños puentes que salvan el río
El empleo posterior en el análisis de las estructuras de fábrica de esta teoría centrada en la resistencia de los materiales ha conducido a aberraciones tanto en la comprensión de su comportamiento como, sobre todo y lo que es peor, en su restauración, dando lugar a intervenciones que, basándose en esa supuesta falta de resistencia, hacían de ellas unas construcciones enfermas necesitadas de tratamientos cada vez más drásticos $\mathrm{y}$, a la postre, dañinos para su estabilidad y conservación material.

En lo que sigue haremos un breve repaso al contenido de una teoría de estructuras centrada en el equilibrio y a los resultados de su aplicación en el caso de la iglesia de Santa Eulalia en Marquínez, Álava (fig. 1). Sin embargo, iremos más allá y este análisis estático se convertirá en un análisis que podríamos llamar diacrónico cuando introduzcamos en él la variable temporal y podamos ver el efecto que sobre la estructura tiene el paso del tiempo, de la progresiva degradación de los materiales, del aumento de la deformación geométrica de la fábrica y de la intervención conservadora llevada a cabo por sus usuarios en distintos momentos, hasta llegar a introducir otra teoría estructural, la de los estados límite, para evaluar hasta dónde podría llegar esa evolución antes de un hipotético colapso².

\footnotetext{
${ }^{2}$ Icomos-Iscarsah, 2001, ya recoge el estudio histórico de la estructura como herramienta fundamental de evaluación de la seguridad de la construcción al declarar: "History is the most complete, life-size, experimental laboratory than man can conceive. It demonstrates how the type of structure, building materials, connections, joints, additions and human alterations have interacted with natural events, such as...»
}

La introducción de esta variable diacrónica en la evaluación de la seguridad de una estructura de fábrica se apoyará en el estudio histórico desarrollado con aplicación de los métodos de la Arqueología de la Arquitectura por los arqueólogos Ismael García e Ibán Sánchez ${ }^{3}$, y podrá llevarnos a una mejor comprensión tanto del comportamiento de la estructura como de su seguridad y, en última instancia, a hacer una propuesta de restauración basada en el respeto a la vida propia del edificio (Fig. 2).

De esta manera, queremos mostrar que el desarrollo de una metodología de estudio de esas estructuras adecua$\mathrm{da}$ a su funcionamiento real ha de pasar por el trabajo de análisis arqueológico de su evolución, ya que ésta podría, en última instancia, dirigirse hacia el colapso del edificio en un plazo indeterminado, y ya que es ese análisis el que nos informa, a través del conocimiento de su comportamiento en el pasado, de cómo podría desenvolverse en el futuro y, en consecuencia, qué posibilidades hay para una hipotética intervención estructural.

\section{La obra de fábrica, un sistema de masas en equilibrio}

Una obra de fábrica abovedada es un sistema de masas en equilibrio en el que no tienen demasiada relevancia ni la resistencia de los materiales que la constituyen ni las

\footnotetext{
${ }^{3}$ García Gómez, 2005, recoge el trabajo de investigación realizado por el Grupo de Investigación en Arqueología de la Arquitectura de la Universidad del País Vasco, UPV-EHU.
} 
Fig. 2. La iglesia de Santa Eulalia desde el noroeste. A la izquierda la casa rectoral, a la derecha el hastial occidental de la nave. Se aprecia el estado general de

fisuración que presenta el hastial occidental de la nave de la iglesia, con grandes grietas que lo cortan prácticamente en toda su altura y en distintos puntos, sobre la ventana y entre ésta y el contrafuerte noroeste. En la casa rectoral se puede ver la gran fisura que parte de la puerta inferior, moviendo las dovelas de su dintel, asciende por el vano cegado intermedio y corta completamente el muro por encima de la ventana geminada, que por su parte ha perdido el parteluz que había de sostener el dintel, ahora sólo empotrado en el lado derecho - sur- del muro. A la derecha de la iglesia asoma la roca que da

origen, tanto geológico como histórico, al edificio

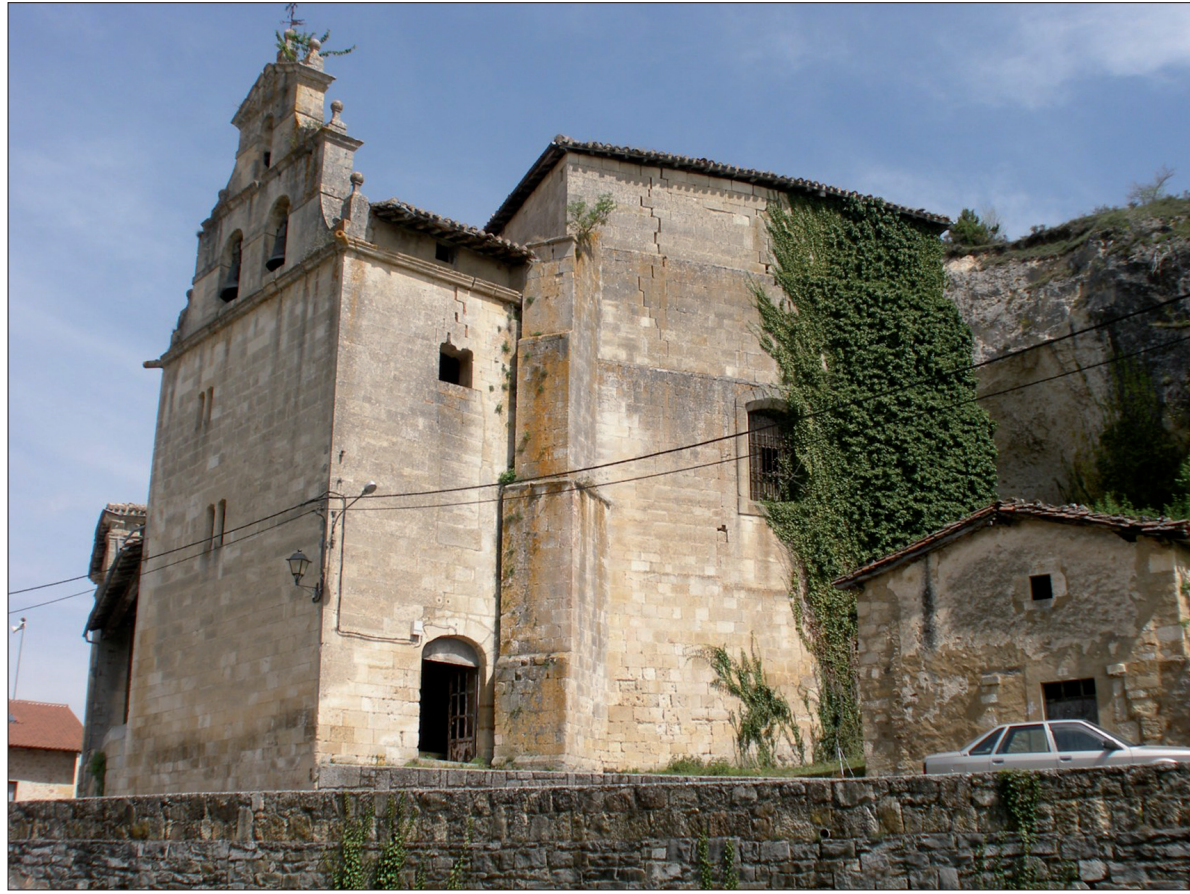

tensiones a que éstos hayan de verse sometidos, dado que éstas van a ser siempre de un rango inmensamente inferior a aquélla. Sólo puntualmente, y lo veremos en el caso que nos ocupa, la magnitud de las tensiones soportadas en los puntos de concentración de esfuerzos llegará a ser un problema para la estabilidad, parcial o global, de la estructura; problema que, por otro lado, en general se verá rápidamente solventado por la enorme capacidad de estas estructuras de encontrar mecanismos alternativos de equilibrio.

Una obra de fábrica es una construcción erigida mediante el sucesivo apoyo de pequeñas piezas de piedra o ladrillos unas sobre otras. La ligazón entre las distintas piezas no se produce, contra lo que parece, mediante los morteros de la fábrica, sino mediante el peso de unos materiales descansando y cargando sobre los de más abajo; los morteros son, de hecho, más una especie de «colchones» que facilitan el contacto entre las distintas piezas, amoldándose a las formas de sus superficies, que un «pegamento» que las mantenga unidas. Entender este mecanismo permite comprender de qué modo se sujetan las bóvedas y los arcos y cómo se comportan globalmente estas estructuras. La presión mutua ejercida por las dovelas de un arco entre sí y contra los muros o pilares que las sustentan las mantiene unidas y en el aire. La falta de presión - compresión en términos estructurales- hace que en algunos puntos se separen las distintas partes y aparezcan grietas; pero la formación de éstas no significa la existencia de tracciones en la fábrica, ya que estas no pueden darse en este tipo de construcciones.

\section{Diagramas de descenso de cargas}

El análisis estático de la estructura se basa en la evaluación de los pesos propios de todas esas partes de la construcción, de su ubicación real en el espacio y de las relaciones de contacto entre ellas para construir un diagrama que representa el modo en que esos pesos se traspasan de unas partes a las otras hasta llegar al terreno firme. Las diferentes magnitudes de los pesos serán fundamentales a la hora de establecer su sistema de equilibrio y de evaluar la capacidad final del firme de asiento, variable ésta fundamental en el estudio de la evolución temporal del equilibrio.

Como resultado representativo del análisis obtendremos una serie de diagramas de descenso de cargas, en los que se dibujarán las trazas que los vectores representativos de los pesos van dejando en su recorrido por la fábrica hasta llegar al terreno de apoyo que las ha de resistir en última instancia (fig. 4). Durante ese «recorrido», el diagrama mostrará la suma, en magnitud y dirección, de los pesos que se van incorporando sucesivamente desde la parte más alta de la estructura —inicio del diagramahasta la cimentación — final—. Para la construcción del diagrama se seguirá una serie de reglas, como la de que las cargas se suman siempre "hacia adelante», según se van incorporando a ese recorrido o «descenso», y que la traza 


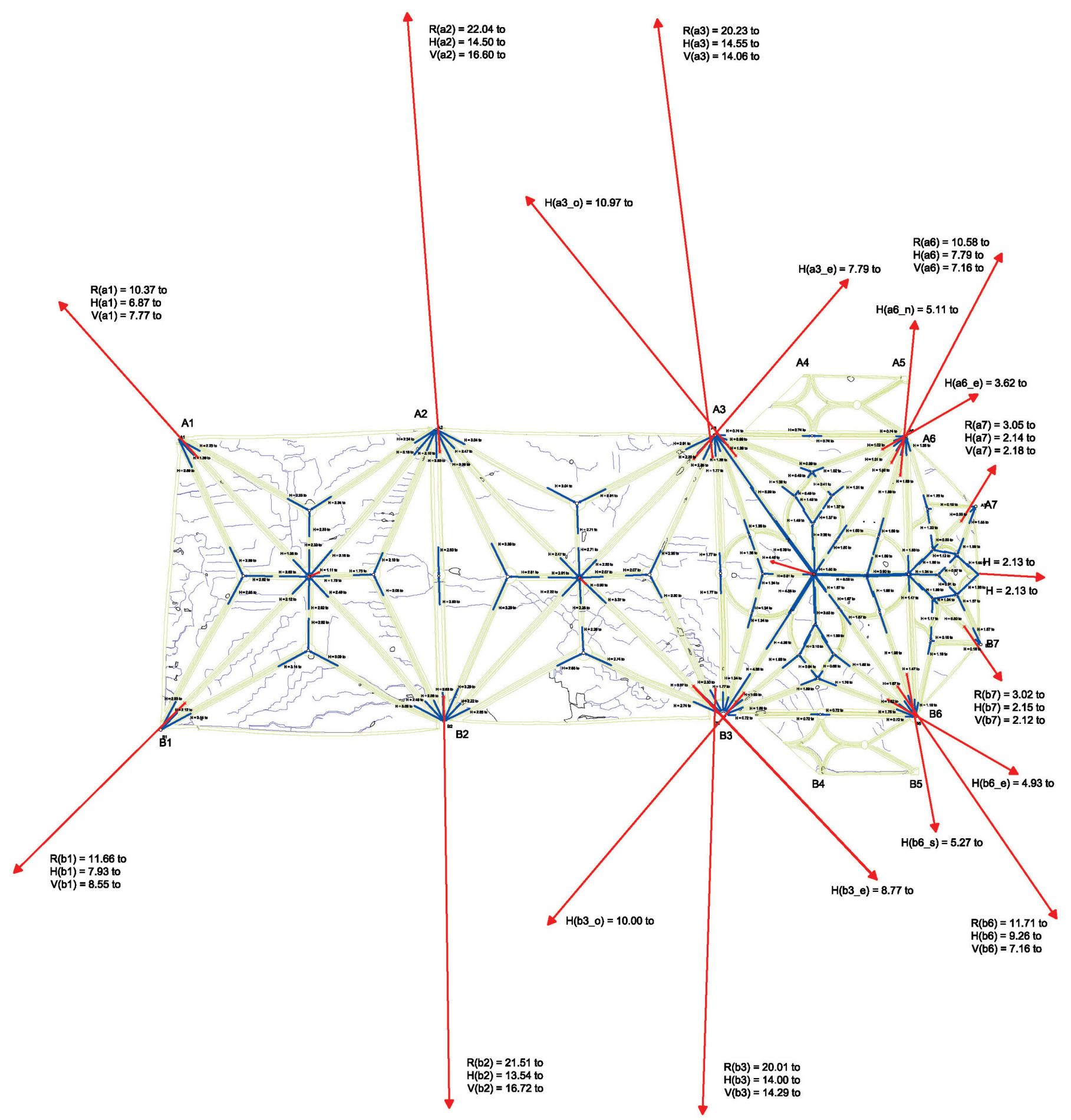

Fig. 3. Diagrama de esfuerzos interiores en los nervios de las bóvedas y resultantes sobre los muros de la iglesia

resultante no puede salir del área resistente de los elementos constructivos del edificio (fig. 5).

En la figura 3 se observa cómo los dos tramos centrales de las bóvedas son los que producen mayores empujes laterales, lo cual es lógico resultado de ser estos puntos donde descarga un mayor número de nervios. Sin embargo, en los apoyos A3 y B3, en las pilastras de entrada a la cabecera, esos empujes pueden descomponerse en dos direcciones aproximadamente coincidentes con las de los dos muros que forman ángulo en esos puntos. Este sistema de quiebros en los muros es propio de la construcción de tradición gótica y resulta muy efectivo estructuralmente porque admite grandes variaciones tanto en la magnitud como en la dirección de esos empujes a lo largo del tiempo. 


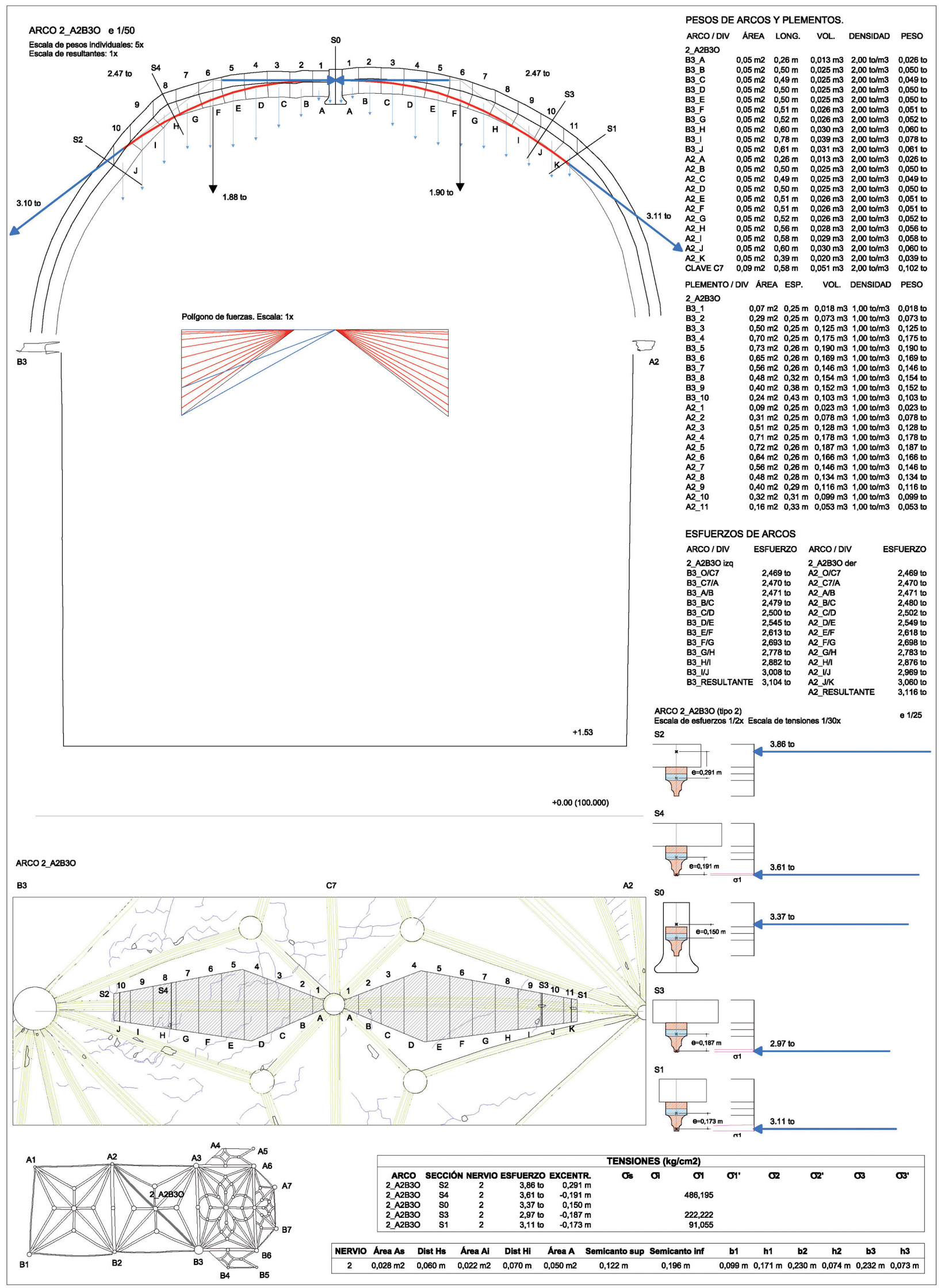

Fig. 4. Diagrama de descenso de cargas en un arco diagonal, en el que se aprecia cómo la curva de presiones —en rojo- tiene un difícil ajuste en el interior de la sección resistente del arco quebrado. Análisis de los pesos, esfuerzos y tensiones en las distintas secciones transversales del arco 
Por el contrario, en el tramo central del aula, apoyos A2 y B2, el empuje es claramente perpendicular al muro y no admite otro sistema de contrarresto que la colocación de un contrafuerte, lo cual se da en el lado norte, donde el muro se construye en correspondencia con las bóvedas y por tanto se dota de ese refuerzo, mientras que no se produce en el lado sur, donde el recrecido del muro correspondiente a la fase de construcción de las bóvedas debe adaptarse a la geometría y espesores del muro inferior ya existente desde fases anteriores. Por otro lado, se aprecia que la deformación padecida ya por los nervios de las bóvedas y el análisis de los esfuerzos en su interior obliga a desplazar el diagrama de cálculo estático —el antifunicular de las cargas - hacia el lado norte, con lo que en las claves de las bóvedas aparecen esfuerzos desequilibrados que tienen esa dirección —en rojo-, lo cual viene a indicar que el conjunto de las bóvedas tiende a descargar y desplazarse hacia el lado norte de la iglesia en respuesta a la debilidad del muro sur enormemente desplazado de su posición aplomada inicial, ofreciendo así una demostración de la alta hiperestaticidad que se suele atribuir a este tipo de construcciones.

En la figura 4, a partir de las distintas resultantes de estos análisis, efectuados para cada arco con la distribución del peso de las bóvedas marcada en el dibujo inferior, se ha construido el diagrama anterior para el conjunto de las bóvedas. Y con la suma de las resultantes horizontales más los correspondientes pesos se inicia el estudio del descenso de cargas hasta el terreno del diagrama siguiente. En la parte superior derecha se muestra el análisis de los pesos basado en los análisis de la composición de arcos y bóvedas y en los datos sobre sus materiales constituyentes — densidad, resistencia-; bajo estas tablas se representan los esfuerzos en las distintas secciones del arco, viéndose que la excesiva excentricidad de éstos en las secciones S3 y S4, las situadas aproximadamente a un tercio del desarrollo de la directriz del arco, producen unas grandes tensiones unitarias, que se especifican en la tabla inferior. Estas grandes tensiones superan la capacidad resistente de la piedra y provocan la fractura del material por sobrecompresión, con pérdida de sección resistente y progreso consecuente del daño, y forman de esta manera las rótulas o charnelas de giro de unos bloques respecto a otros.

El resultado que se demuestra en la figura 5, al no encajar con la teoría de estructuras aplicada, requiere encontrar una explicación plausible que justifique la estabilidad de la esquina. Para ello podemos acudir a la existencia de una cuña invertida en los dos muros que convergen en la esquina, formada mediante el sucesivo voladizo de los sillares de una hilada sobre la inferior, cuña que viene a suponer una sobrecarga en la parte inferior del muro que tiende a estabilizarlo. En todo caso, el resultado final es que el equilibrio de esta esquina requiere la movilización de mecanismos de resistencia de la estructura poco seguros y por tanto inestables. En los dibujos de las sucesivas plantas se aprecia la traza de la resultante a distintas alturas, junto al análisis de los pesos, esfuerzos y tensiones resultantes en las distintas secciones de cada apoyo, obtenidas mediante el cociente de esos esfuerzos por las secciones transversales consideradas, cuyas superficies efectivamente actuantes se han maximizado para permitir cumplir con las limitaciones de resistencia propias de la fábrica, cuando realmente esas tensiones tendrán una distribución irregular en la sección resistente y alcanzarán un máximo en la fibra exterior, más comprimida, que podría llegar a dañar a la piedra, nuevamente provocando inestabilidad por pérdida de material resistente.

\section{Esfuerzos y tensiones}

A partir de esos diagramas se pueden evaluar los esfuerzos que soporta cada elemento, como la suma vectorial -es decir, con magnitud y dirección - de los pesos que se encuentran gravitando por encima de él, y deducir del cociente de estos esfuerzos por las secciones resistentes útiles de los elementos la magnitud de las tensiones a que trabajan esos elementos, cotejándolas eventualmente con sus capacidades resistentes para deducir unos coeficientes de seguridad frente a una hipotética rotura del material que pudiera provocar daños en la estructura.

Este análisis general de la estructura, que en su aplicación concreta exige tanto el conocimiento preciso de la geometría y composición material de la estructura como un análisis previo de su comportamiento general para plantear una estrategia de fraccionamiento de la construcción que lo haga practicable, nos llevará a localizar los posibles puntos críticos para la estabilidad y, eventualmente, nos indicará las zonas de posible intervención de consolidación o refuerzo.

\section{Mecánica de las fábricas}

Sin embargo, el análisis descrito no llegará a ser concluyente respecto a la seguridad de la estructura mientras no considere también la posible evolución de ésta a lo largo del tiempo. Las fábricas se encuentran constantemente sometidas a los efectos de los cambios higrotérmicos diarios y estacionales, en una serie de movimientos cuyo efecto ponderaremos mediante otro tipo de análisis, que podríamos llamar «diacrónico», en el que se evalúa la 


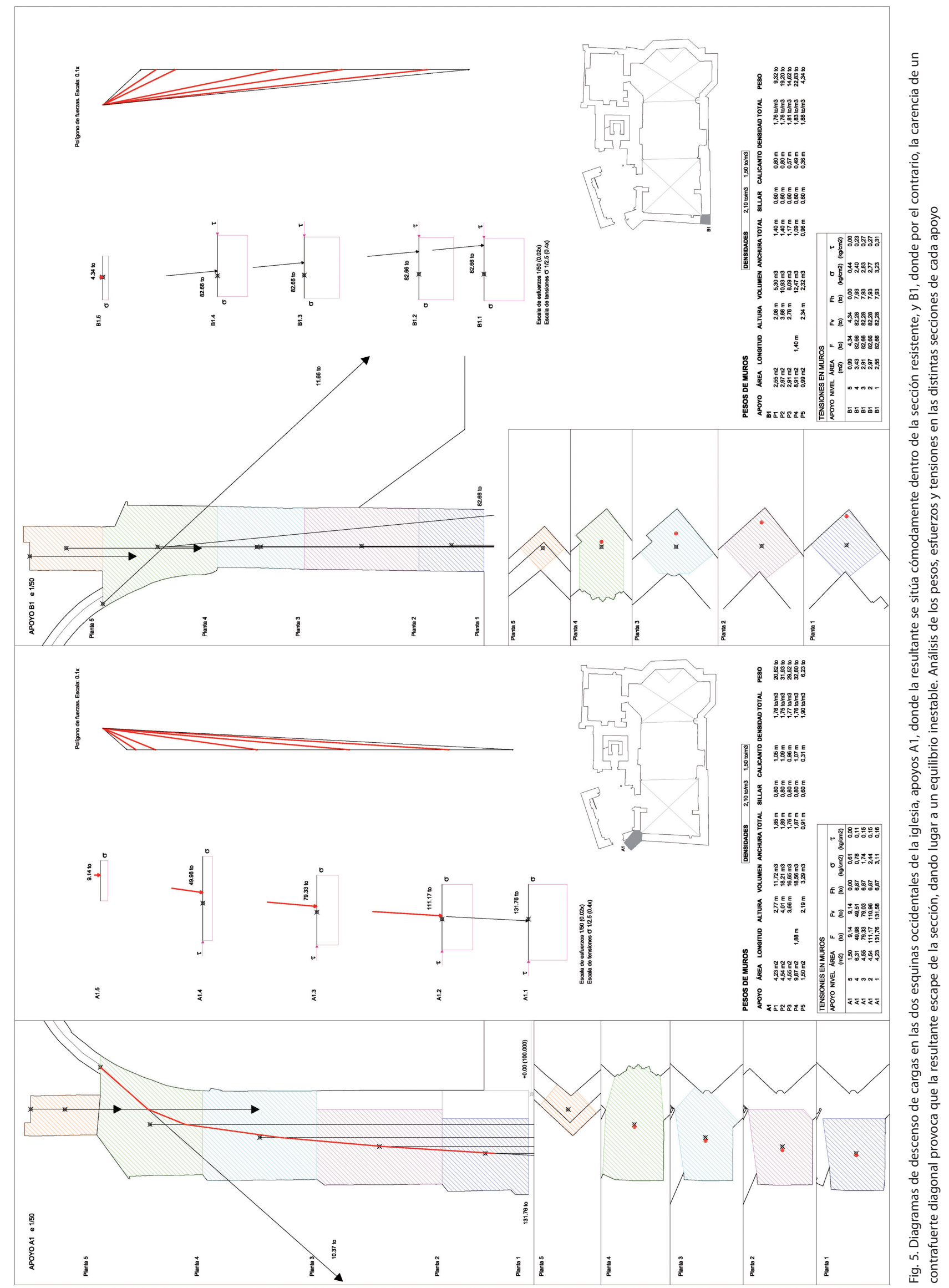




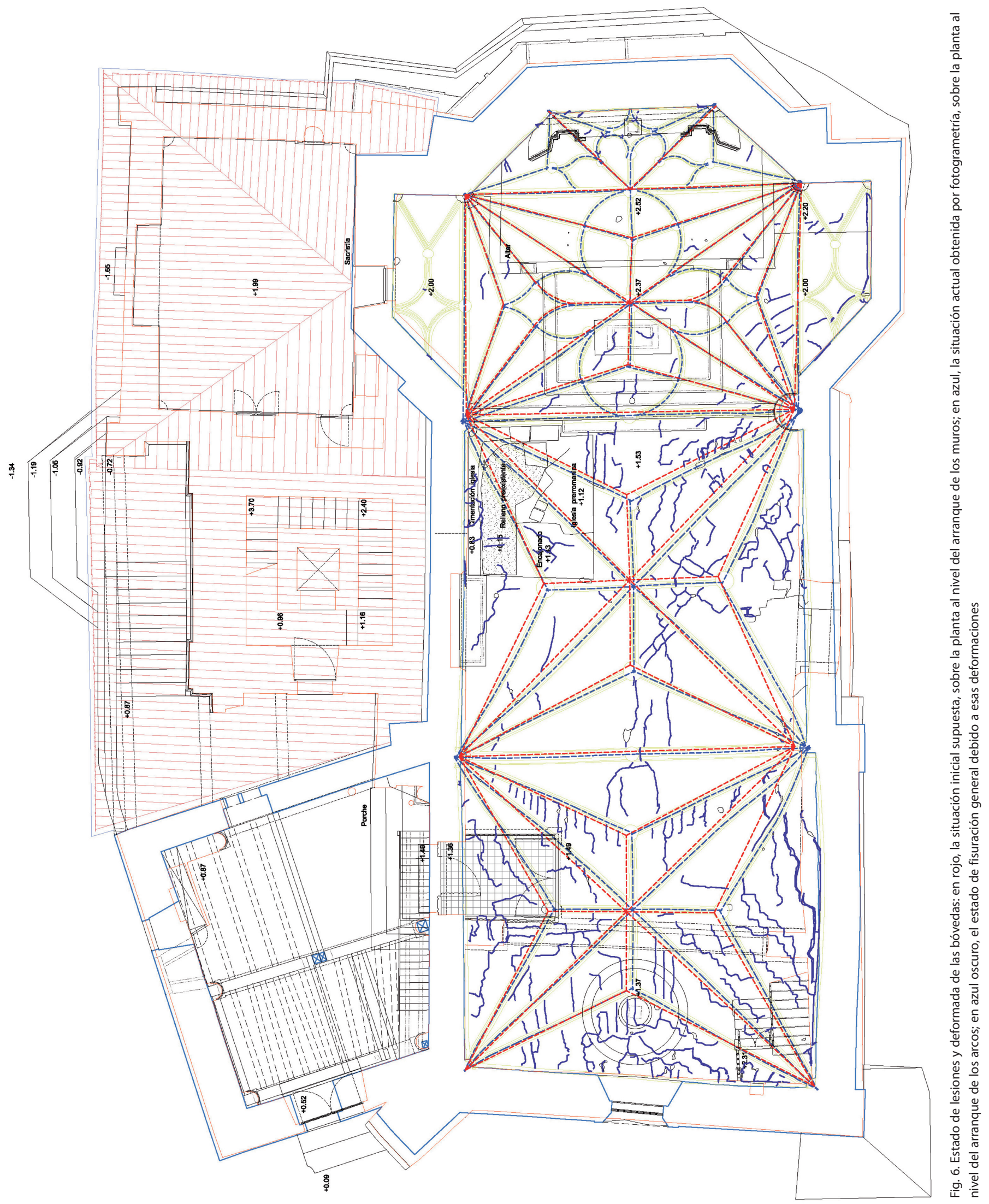


mecánica completa de la estructura de fábrica, es decir, no sólo sus posibles e hipotéticas situaciones de equilibrio estático correspondientes a distintos estados de cargas - pesos propios y solicitaciones temporales-, sino el modo en que la estructura se mueve en respuesta a esas otras solicitaciones variables.

\section{Movimientos cíclicos}

La existencia de ciclos higrotérmicos diarios y anuales —además de los más irregulares ciclos de sequía y humedad, o de altas y bajas temperaturas globales - hace que la mayor parte de los movimientos que padecen las estructuras - de fábrica o de cualquier tipo- sean una respuesta en forma de vaivén a las solicitaciones que esos saltos higrotérmicos suponen para ellas, manifiesta en dilataciones y contracciones de su extensión física. Estos movimientos tienen como efecto más inmediato y general la aparición de pequeñas fisuras en las zonas donde los cambios de extensión de la fábrica producen movimientos en direcciones opuestas. Estas fisuras se vendrán a convertir en «juntas de dilatación» de la estructura, necesarias para disipar las tensiones producidas por esas solicitaciones cíclicas e impedir su concentración en determinadas partes cuyo fallo resistente podrían llegar a provocar.

\section{Movimientos progresivos}

Sin embargo, no todos los movimientos son estrictamente cíclicos; de hecho ninguno lo es, pues las fábricas nunca retornan a su exacta posición inicial debido a las pequeñas dislocaciones de los materiales que se producen en cada ciclo. Pero además, los asientos en el terreno de apoyo de la estructura debidos a la evolución natural de éste —consolidación de las arcillas, lavado y desplazamiento de las arenas, por ejemplo-, o los reacomodos de la fábrica debidos a la degradación de sus materiales constitutivos, singularmente sus morteros de unión, son movimientos no cíclicos sino progresivos que alteran constantemente la geometría de la fábrica, y a veces también su composición material, provocando deformaciones cada vez mayores acompañadas de las correspondientes e inevitables lesiones.

En la figura 6 se ha efectuado la restitución de las trazas originales de las bóvedas mediante la eliminación del desplome medido topográfica y fotogramétricamente en el edificio actual, pues se supone que en el momento de construirse las bóvedas los muros se encontrarían sensiblemente aplomados. Al devolver esos puntos a su posición inicial y unirlos entre sí se encuentra esa traza original supuesta, que exige también desplazar la posición de las claves e intersecciones entre los distintos nervios. La deformación lateral de éstos, que no sigue el plano en que se encuentran contenidos los nervios sino la dirección de la resultante de la acción de todos ellos, produce en los nervios no paralelos a esa dirección - todos excepto el arco perpiaño en el caso más claro del apoyo B2- una torsión de su directriz que viene a producir nuevas sobrecompresiones en las zonas de arranque de los arcos, con la consiguiente pérdida de material y progreso sucesivo del daño hasta que el movimiento se detenga y se puedan reparar las pérdidas.

Las lesiones que se muestran en la figura 7 vienen a dibujar la formación de un gran arco de descarga en el tramo central del muro del aula, cuyo centro coincidiría con la pilastra B2, punto donde se concentran los empujes de la bóveda. Sin embargo, la magnitud de este empuje no justifica por sí sola la formación de ese sistema de fisuras, que se debe explicar además por el asiento del tramo central del muro, asiento que se aprecia claramente en la figura 14. Por su parte, los perfiles de corte de los muros este y oeste muestran el ligero desplome que ambos padecen hacia el exterior de la iglesia, consecuente tanto con el sistema de empujes de las bóvedas, que tienden a abrir el edificio en su parte alta, como con los asientos del terreno, que son mayores en las caras externas de los muros debido a la excentricidad de la distribución de los esfuerzos y tensiones que éstos aplican en el suelo.

En la figura 8 se aprecia cómo un sistema de tres grandes fisuras cortan y desgajan de abajo arriba el muro del fondo, hastial occidental de la iglesia, prácticamente en toda su altura (ver fig. 2). En los cortes de los muros laterales se aprecia también el gran desplome que tiene la fachada sur y que no es igual en todos sus tramos de distintas alturas y correspondientes a distintas fases de obra, sino que son progresivamente más acusados según subimos, lo que vendría a demostrar que es el muro el que no es capaz de mantener su forma ante los empujes de las bóvedas debido a su mala consistencia y a la falta de los necesarios contrafuertes, siendo el asiento del terreno responsable sólo de los posibles desplazamientos verticales. Finalmente, en el muro norte de la casa rectoral se aprecia una diferencia de desplomes distinta a la anterior, es decir mayor en la parte inferior, hasta la cornisa, que en la superior, la espadaña, lo cual se explica por los distintos tiempos de evolución del asiento en el terreno que provoca estos giros.

\section{Sistema de bloques}

La formación de los sistemas de lesiones — grietas — de las fábricas produce la división de la estructura global en partes más o menos netamente separadas entre sí por ellas, 


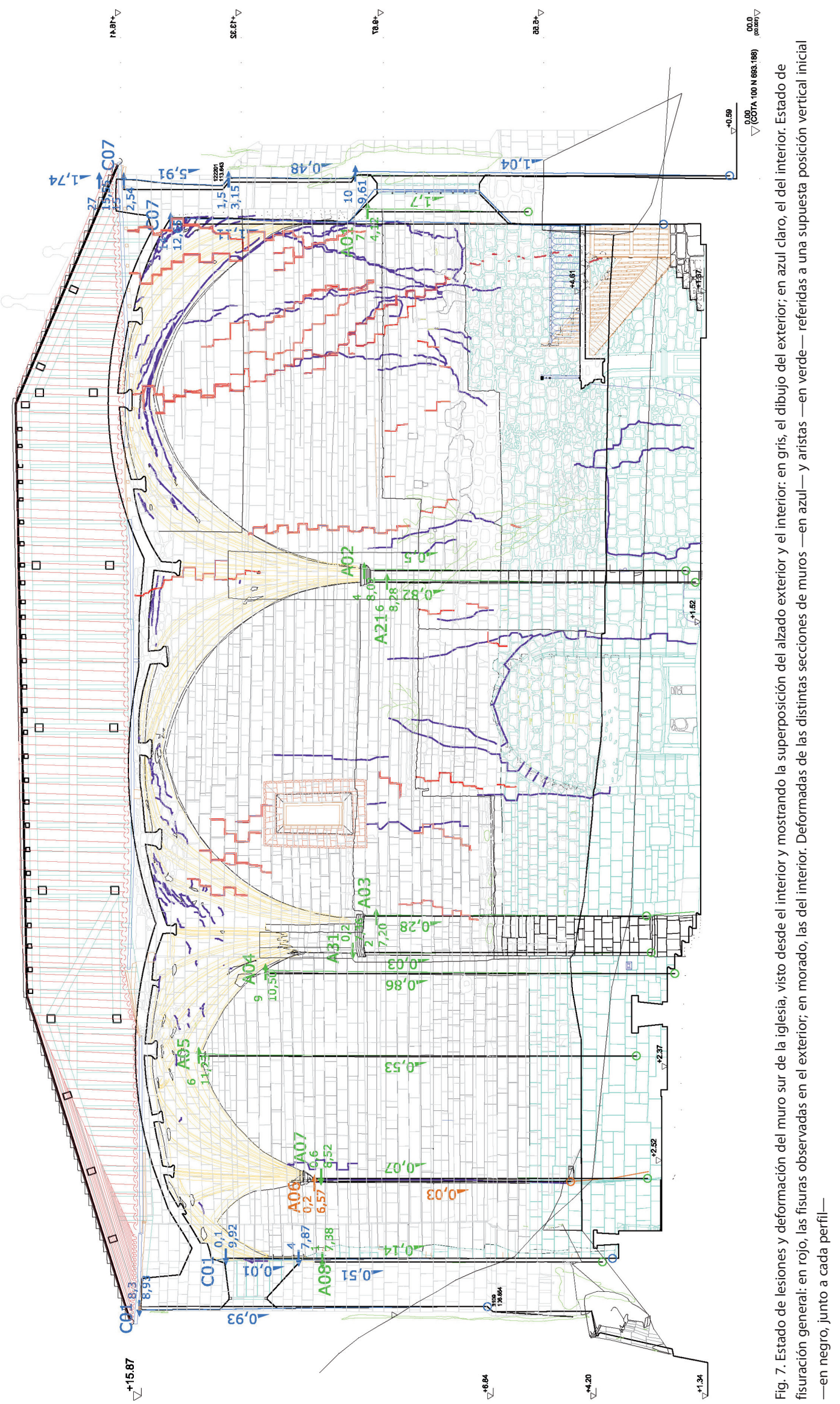




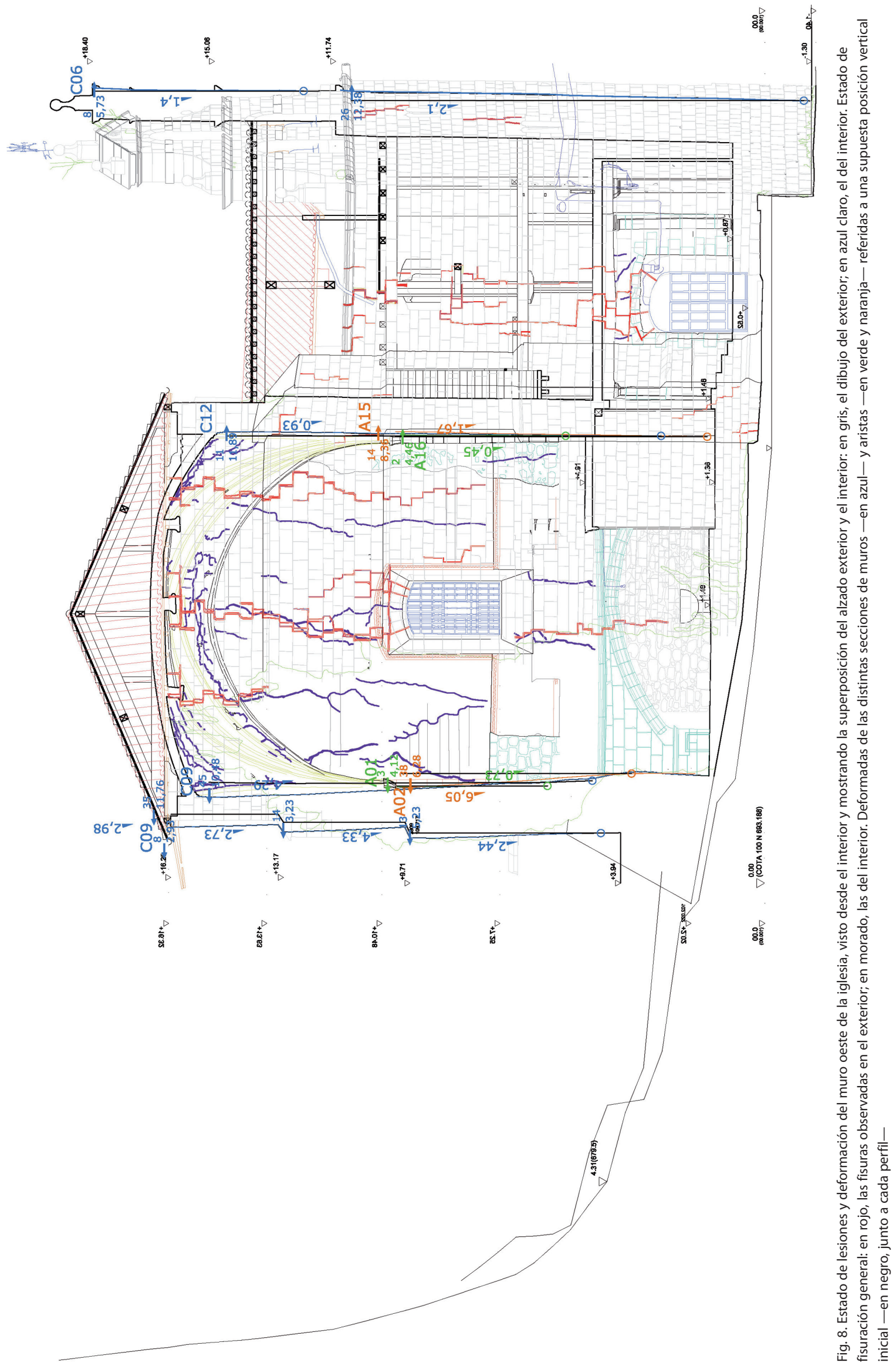


conformando un sistema de bloques constructivos cuyas zonas de contacto devienen en los puntos donde se concentrarán los movimientos relativos, esto es las articulaciones o charnelas de giro de unas partes respecto de las otras.

\section{Equilibrio evolutivo}

En definitiva, la estructura se habrá convertido en un conjunto de elementos constructivos en perpetuo movimiento cuyo equilibrio más o menos inestable habrá de ser objeto de nuestro análisis. Los movimientos, al igual que los descensos de cargas, habrán de seguir ciertas reglas, como son que en general dentro de la estructura -es decir, en aquellos movimientos en que no incida el posible asiento del terreno o la degradación de los materiales- serán giros de unas partes respecto a otras, pues es condición necesaria del equilibrio que algún extremo de cada bloque quede sujeto, oscilando, en los extremos de otros bloques, conformando al final un sistema de movimientos con ciertos grados de libertad que hay que evaluar; la otra regla fundamental es la de que esos movimientos tienen un límite de amplitud en algunas de sus direcciones posibles, límite evidentemente marcado por la posición de otros bloques cercanos con los que tropezará, evitándose así en general los posibles colapsos. Por el contrario, los movimientos de desplazamiento que tienen su origen en asientos o degradación material, así como aquellos que no encuentren tope en otros bloques, serán los que puedan dar lugar a esos colapsos y son, por tanto, los que más interesa analizar para el control de la seguridad de la estructura.

\section{Los estados límite}

Ambos análisis deberán considerar cuál es el estado límite al que puede llegar la estructura en esa evolución antes de su colapso, parcial o total. La noción de estado límite es relativamente moderna en el análisis de estructuras y se encuentra desarrollada sólo parcialmente en la teoría de estructuras de fábrica — vale decir que sólo en su formulación general ${ }^{4}$ - , sin que se hayan presentado todavía metodologías completas de análisis aplicables a los edificios de fábrica realmente existentes. Se cuentan dos tipos de

\footnotetext{
${ }^{4}$ Heymann, 1969/1995 y 1999, contiene la formulación más clara del análisis límite de estructuras de fábrica y formula la condición de seguridad estructural de un arco o una bóveda como su capacidad para albergar distintas «curvas de presiones" correspondientes a distintos estados de carga o de deformación impuesta exteriormente. Huerta, 2004, recoge la moderna formulación del análisis límite de estructuras de fábrica y una revisión del proceso histórico de investigación que lleva hasta ella. Di Pasquale, 1996, hace una revisión menos teórica y más cercana a una historia de la construcción y de la propia teoría de arquitectura.
}

estado límite, es decir, dos posibles situaciones de colapso de la estructura, la que se produce por fallo del material debido a las altas tensiones que en algún punto haya de soportar, superiores a su capacidad resistente, y la que se produce por inestabilidad de alguno -o todos- los bloques del sistema, que ya dijimos se encuentra en un estado de equilibrio cambiante. Ambos, en todo caso, pueden ser concurrentes y provocarse mutuamente: un movimiento excesivo de una parte de la fábrica conducirá a una concentración de tensiones en alguna sección resistente, que podría romperse y provocar un nuevo y mayor movimiento de la estructura, movimiento que en el límite sería el de su colapso.

El corolario del análisis estático será la evaluación del estado límite de tensiones, con una revisión de esfuerzos y tensiones en las distintas secciones resistentes de la estructura a partir de los diagramas de descenso de cargas en relación con la geometría —sección- y el material - resistente- Esta evaluación de tensiones de trabajo tiene siempre un grado de indeterminación, mayor o menor en función del mejor o peor conocimiento que tengamos de esas geometrías y materiales constituyentes, por lo que, a la manera habitual de los análisis de estructuras más convencionales, emplearemos en ella distintos coeficientes de ponderación que nos permitan operar con márgenes fiables de seguridad.

Por su parte, el corolario del análisis del movimiento de los bloques será la evaluación del estado límite de equilibrio, en la que se tratará de encontrar la manera en que los posibles distintos giros y desplazamientos podrían combinarse para provocar una inestabilidad global de la estructura, formando un mecanismo de colapso. La descripción de estos posibles mecanismos de colapso, con la identificación de los esfuerzos o daños materiales - límite de tensiones- que podrían producirlos es la segunda parte del análisis seguro de la estructura.

\section{Evolución temporal}

Hasta aquí, la descripción del comportamiento de una estructura de fábrica y la propuesta de un posible método de análisis estructural basado en modelos de estados límite de equilibrio y tensiones resultan aplicables a cualquier edificio de esta clase. Sin embargo, las estructuras realmente existentes han venido adoptando sucesivos estados de equilibrio en función de las variaciones en las condiciones de su entorno, desde el clima a los movimientos del terreno y a la degradación de sus materiales, que habrán dado lugar en ocasiones a intervenciones de reparación o refuerzo por parte de sus habitantes con objeto de evitar que los 
evidentes daños que el edificio viniera padeciendo llevaran a su pérdida.

Los edificios son una parte de la naturaleza aislada de ésta por la acción humana, por el artificio, para satisfacer unas necesidades que son propias sólo de nuestra especie. Pero este aislamiento nunca es completo ni podrá serlo: los materiales constructivos siguen siendo parte de la naturaleza y no se puede detener su evolución. Sólo podremos, en ocasiones, tratar de corregir los efectos que consideramos perniciosos de entre los que ha producido el paso del tiempo.

Las construcciones a las que nos enfrentamos se pusieron en pie hace ya varios o muchos siglos, y desde entonces han venido estando sometidas a la degradación provocada por los agentes naturales, activos en ciclos diarios, anuales o de ritmos más largos e irregulares, de muchos de los cuales desconocemos el historial de comportamiento. Frente a esa evolución natural y a lo largo de esos siglos, los que habitaron en cada edificio han venido haciendo lo necesario para mantenerlo útil, lo que nos lleva a la consideración del edificio actual como resultado de una serie de intervenciones humanas a partir de la construcción inicial, fuera ésta la que fuese y aunque no nos quede de ella más que un recuerdo inmaterial, y cuyo objetivo siempre fue mantener esa utilidad en un mundo cambiante, tanto en lo natural como en lo cultural.

Pero además, otras condiciones del edificio, su utilidad o significado social, podrán haber variado en el tiempo, requiriendo también otras intervenciones que habrán modificado sus condiciones de equilibrio y su modo de responder a las variaciones de su entorno natural. $\mathrm{Y}$ todo ello viene a dificultar, hasta a veces invalidar, el sencillo análisis estructural que hemos visto, exigiendo un nuevo enfoque que permita introducir en sus resultados el efecto de los cambios de fisonomía de la estructura debidos a la acción humana.

La herramienta que permite hacer un análisis pormenorizado de cómo se han venido sucediendo estos cambios será la de la lectura estratigráfica de sus fábricas y su reflejo sintético en el diagrama temporal de su secuencia, fundamental a la hora de identificar no sólo el orden en que tales intervenciones se han realizado sino también qué partes de la estructura se han visto afectadas por cada una de ellas. Pero puesto que los dos recorridos descritos dejan huellas en el edificio, el proceso natural en forma de degradación constructiva, erosión de los materiales o deformaciones y grietas, y la historia cultural en forma de reparaciones, ampliaciones o demoliciones constructivas, debe ser posible hacer una interpretación conjunta de ambos procesos, construir un diagrama temporal que cuente los dos procesos como una sola historia, la que realmente conduce al edificio que tenemos entre manos.

$Y$ sin embargo, cuando estudiamos la historia del edificio nos centramos en esa serie de intervenciones humanas y sólo indagamos en los procesos naturales como causantes de problemas en los edificios que aquéllas han tratado de solventar. De este modo los estudios históricos soslayan el paso del tiempo transcurrido en los procesos naturales, cuyas trazas sólo aparecen fugazmente en sus intersecciones o cruces con las de la representación del tiempo histórico.

El caso que se presenta muestra de qué manera ese diagrama se completa y modifica con la introducción de otra secuencia, la de la evolución estructural «natural», imbricada con la de las distintas obras de reparación o modificación «artificial» de la estructura, y, a la vez, de qué manera éste sirve para mejor interpretar el sentido de aquélla y, en última instancia, para valorar la seguridad global que la estructura tiene ahora mismo y la posible necesidad de obras de reparación 5 .

\section{Estudios realizados}

Los estudios previos realizados entre 2002 y 2004 por encargo de ARABARRI contemplan:

- Estudio constructivo del edificio y el terreno, incluyendo: estudio geotécnico parcial del suelo en torno a la iglesia y del macizo rocoso situado al sur; estudio constructivo de la composición constructiva de las fábricas y análisis de los materiales constituyentes sobre muestras extraídas de las fábricas; localización de grietas y estudio de su evolución durante un año mediante monitorización discreta —no automatizada - de sus movimientos en algunos puntos señalados; y análisis estructural de algunas secciones constructivas por el método de elementos finitos ${ }^{6}$.

- Documentación fotogramétrica tridimensional, de los paños verticales interiores de la iglesia y exteriores del conjunto de los muros ${ }^{7}$.

- Estudio arqueológico de la evolución constructiva de las fábricas y excavación parcial de restos constructivos anteriores en el interior de la iglesia 8 .

Dentro del proyecto de restauración estructural ${ }^{9}$, entre 2004 y 2009 , se han realizado los estudios:

\footnotetext{
5 Brogiolo, Gian Pietro, 1995.

${ }^{6}$ LABEIN, S.A.

7 AGROCARTO, S.A.

${ }^{8}$ GRUPO DE INVESTIGACIÓN EN ARQUEOLOGÍA DE LA ARQUITECTURA DE LA U.P.V.

${ }^{9}$ LATORRE Y CÁMARA, S.L., arquitectos.
} 


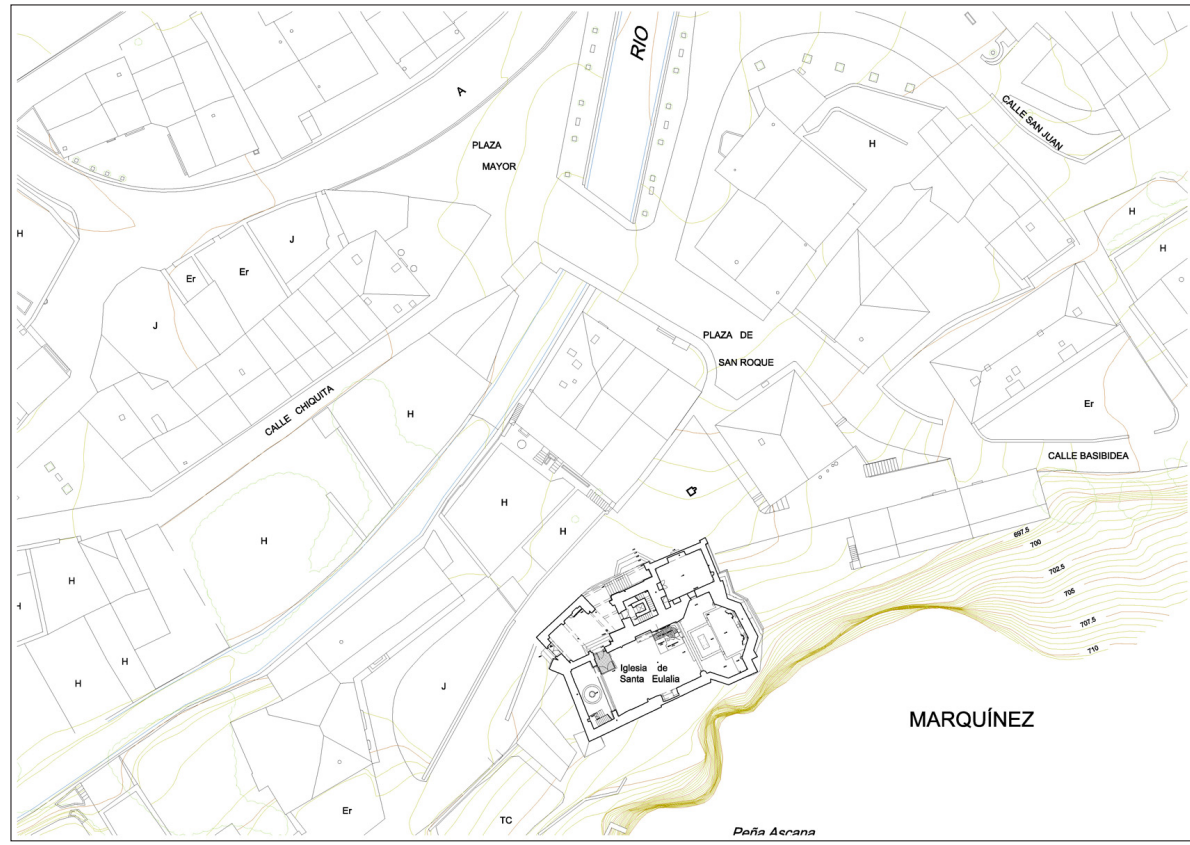

Fig. 9. Situación de la iglesia de Santa Eulalia en el pueblo de Marquínez, con la topografía del roquedo al sur y el río, encauzado, al norte. Se aprecia la gran cercanía entre ambos accidentes y que, de hecho, la iglesia se construye justamente en el tramo en que esa cercanía es mayor, es decir donde los cambios en la composición estratigráfica del terreno son más rápidos y donde se encuentra una mayor heterogeneidad del suelo
- Medición topográfica precisa de las deformaciones de las líneas principales de la estructura del edificio y planimetría completa en dos dimensiones de plantas, alzados y secciones.

- Documentación fotogramétrica tridimensional del intradós de las bóvedas de la iglesia.

- Estudio de revestimientos polícromos y su estado de conservación ${ }^{10}$.

A partir de esos datos, se ha realizado un análisis de la estructura formado por:

- Estudio de las deformaciones, giros y desplazamientos de las fábricas, pérdidas de forma en los arcos y bóvedas, asientos, etc. y de las lesiones producidas en relación con esas deformaciones o movimientos de unas partes de la estructura respecto a otras.

- Secuenciación histórica de los movimientos y lesiones y de sus reparaciones $\mathrm{u}$ otras obras con incidencia en el comportamiento global o parcial de la estructura, de acuerdo con la superposición de los estudios anteriores y del análisis arqueológico.

- Cálculo de líneas de descenso de cargas y resultantes globales por zonas y en el conjunto de la estructura y evaluación de las tensiones resultantes en algunas secciones constructivas de especial relevancia de cara al equilibrio global.

— Estudio de la dinámica de los bloques y sus posibles estados límite de equilibrio, con revisión de la seguridad global de la construcción.

${ }^{10}$ PETRA, S.L.

\section{LA IGLESIA DE SANTA EULALIA DE MARQUÍNEZ}

\section{Descripción: arquitectura e historia}

La iglesia de Santa Eulalia está situada al sur del casco histórico de Marquínez, arrimada a un risco en el lugar donde se produjo el primer asentamiento de la población. Entre el risco y la fachada sur de la iglesia queda un pequeño espacio triangular, notablemente más alto que la calle que discurre al norte y desde la que se accede al edificio. Más al norte de esta calle discurre un pequeño arroyo a un nivel todavía más bajo, de modo que la iglesia se asienta en un terreno con fuerte pendiente hacia el norte. Esta orografía provoca grandes diferencias de altura en los muros de cierre norte y sur, de hasta cuatro metros y medio medidos en el hastial oriental, y de tres metros y medio en el occidental, si bien el nivel del piso de la nave se encuentra un metro y medio más bajo que el del terreno del lado sur, a una cota intermedia entre éste y la calle al norte (fig. 9).

El terreno que conforma ese desnivel está formado por la intersección de dos sistemas de generación del suelo, uno desde el sur, por la caída y compactación de detritus procedentes del roquedo, y el otro en el lado norte, por el aluvión y sedimento de materiales arrastrados por el río. Esta combinación produce la formación de un suelo muy heterogéneo constituido por estratos o lentejones variables en extensión y espesor entremezclados sin una ley clara. Esta heterogeneidad puede ser responsable de algunas de las diferencias de comportamiento estructural entre las distintas partes de la iglesia, 
Fig. 10. Vista axonométrica desde el noreste, donde se aprecian los cuatro cuerpos de edificación: iglesia, sacristía, casa rectoral y torre campanario - bajo la tejavana intermedia-. Se observa el conjunto de las grietas de la iglesia en la zona de la cabecera y la sacristía, que afecta a los muros en toda su altura en distintas partes, lo que es señal de los grandes movimientos padecidos por el edificio desde su construcción

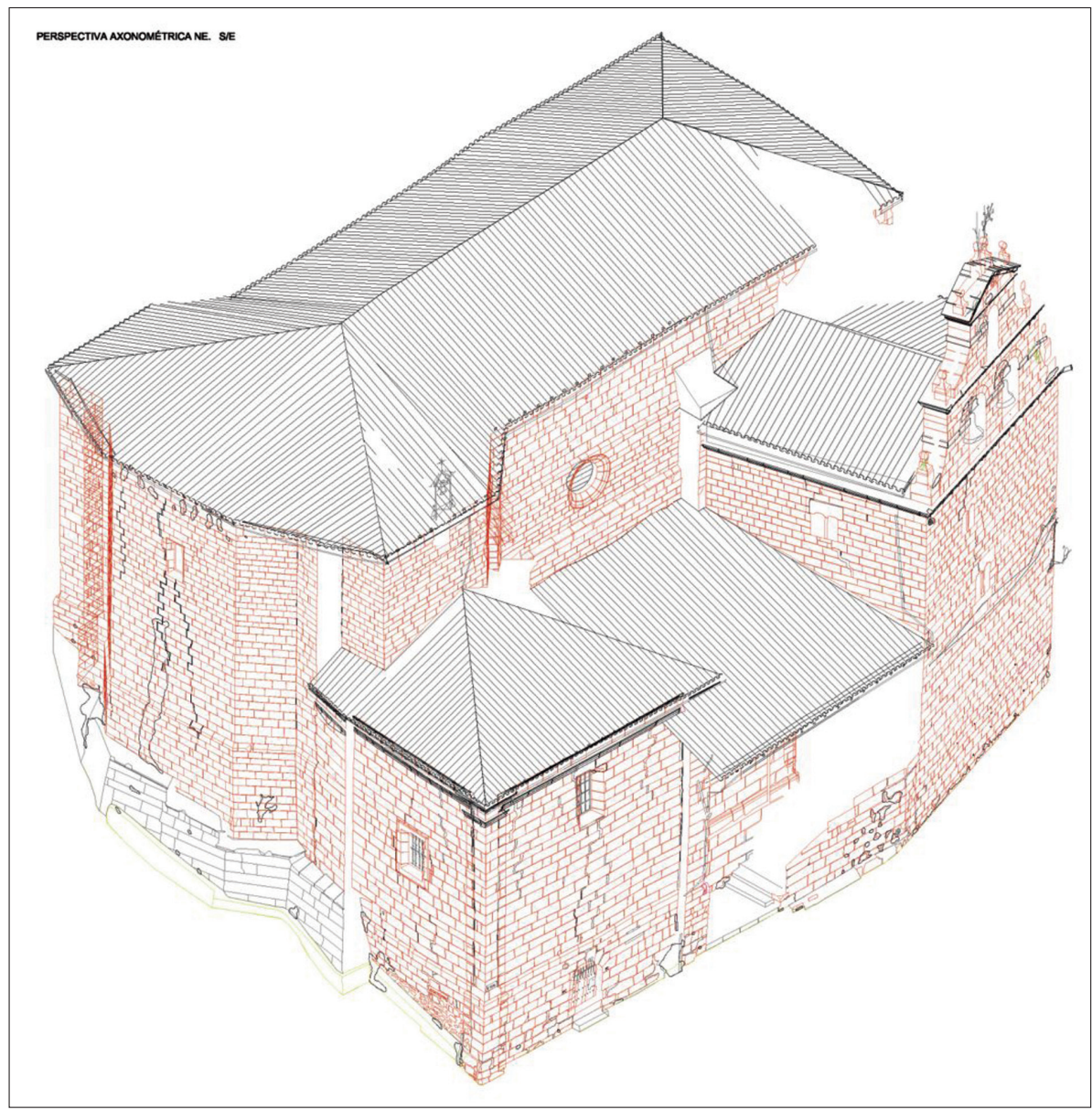

diferencias que en todo caso son más de orden cuantitativo que cualitativo.

El cuerpo principal de la iglesia lo forma una sola nave con tres tramos abovedados: dos de ellos, con planta cuadrangular irregular, forman el aula inicial, construida entre las fases I, II y III, del siglo XIII — los muros- y la fase IV, del siglo XIV —-sus bóvedas—; el tercer tramo, a oriente, forma una cabecera poligonal trilobulada y crea un pequeño seudotransepto con el presbiterio, ya en el siglo XVI, fase V.

Los dos tramos occidentales se cubren con bóvedas de nervaduras con arcos ojivos y terceletes, unidos en sus claves por ligaduras rectas. El tramo de la cabecera tiene un rectángulo central con nervios diagonales y terceletes múltiples unidos mediante ligaduras y combados, y tres tramos en el fondo y los laterales formados por gajos absidales que se unen e integran con esa bóveda central, dibujando una estrella muy elaborada aunque de factura técnica bastante conservadora, con nervios poco esbeltos y lienzos de plementería muy pequeños.

Adosados a estos tres tramos en su lado norte se construyen en distintos momentos tres cuerpos de edifica- ción con finalidades distintas. El primero, junto al tramo de los pies, está formado por un soportal con columnas y un gran arco de entrada y, sobre éste, una casa rectoral con dos plantas, del siglo XV, construida entre las fases IV y V y rematada por un campanario en espadaña del XVIII, fase VIII.

El segundo en orden temporal es el cuerpo cuadrado de la Sacristía del siglo XVII, fase VII, adosado a la cabecera e inicialmente abovedado también con una bóveda estrellada. El tercer cuerpo, junto al tramo central de la iglesia, es una torre campanario inacabada de final del siglo XVIII, fase IX, que, a juzgar por sus dimensiones en planta, podría haber llegado a tener una altura de unos treinta metros. La última construcción, fase $\mathrm{X}$, es un recrecido de los muros para recoger una cubierta de estructura de madera similar a la actual en la primera mitad del siglo XIX. Por último, la fase XI no es más que la reparación de esa cubierta durante el siglo XX (fig. 10).

A partir de esta revisión de las fases de obra conservadas como restos en el cuerpo de la iglesia se puede hacer una restitución de las distintas configuraciones que Santa Eulalia ha ido adoptando a lo largo del tiempo, ver cómo 

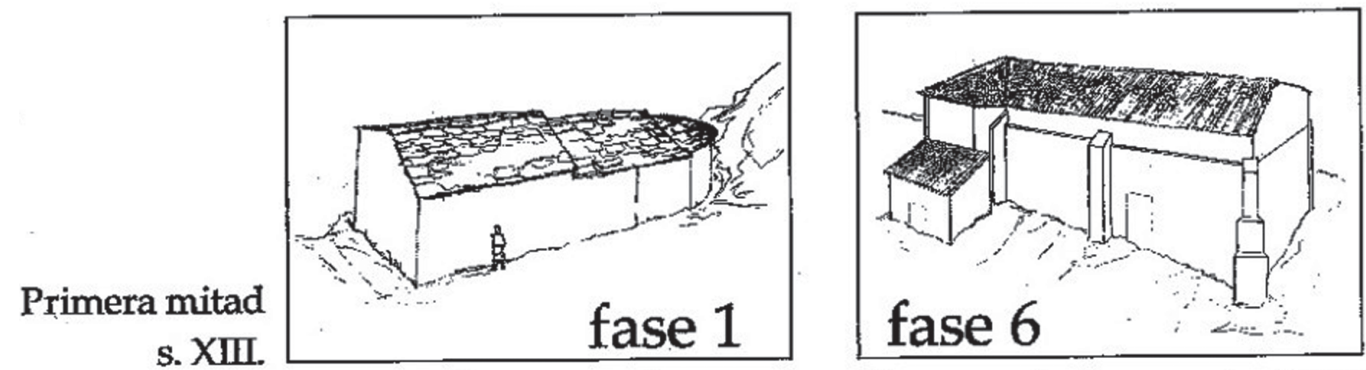

Primera mitad s. XVII.

Fin s. XIII.
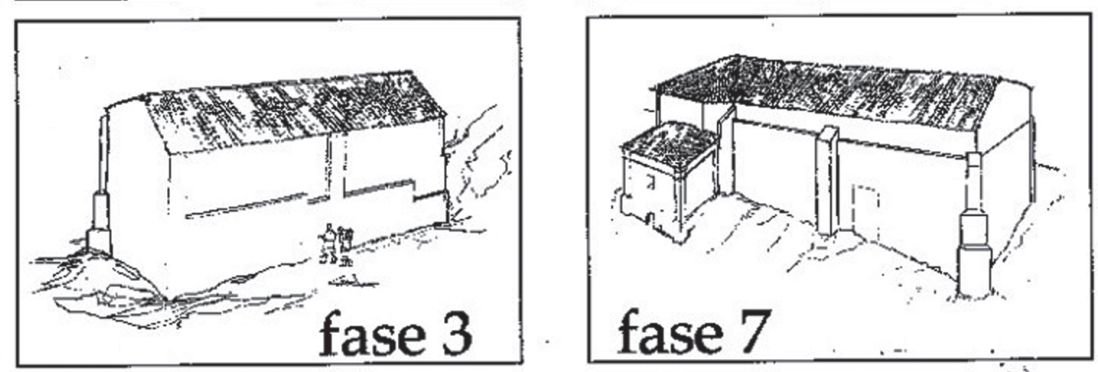

Segunda mitad s. XVII.

ss. XIV-XVI.
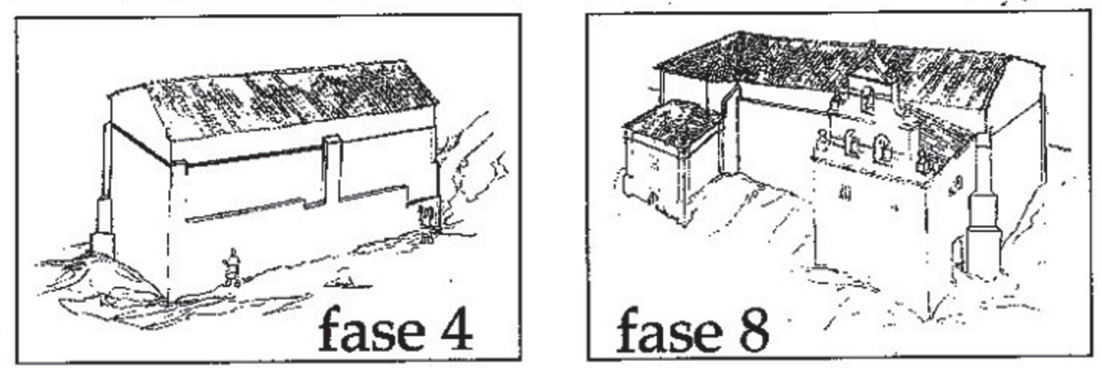

s. XVIII.

Fin s. XVI.
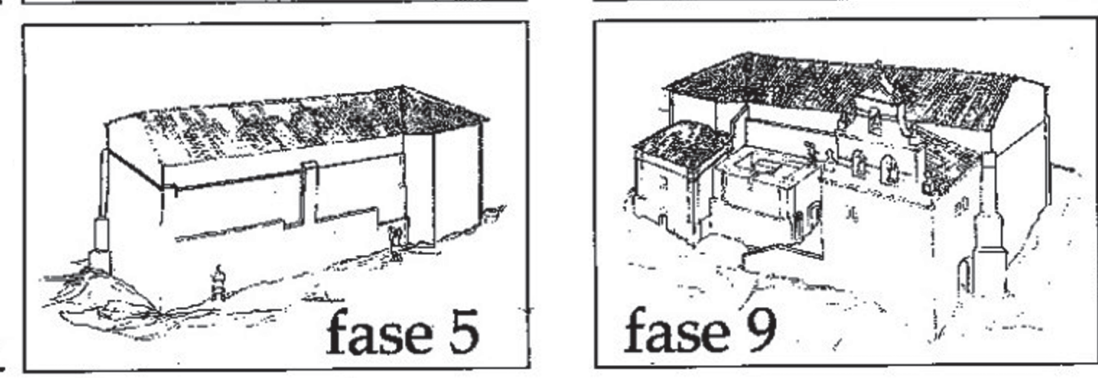

Fin s. XVIII.

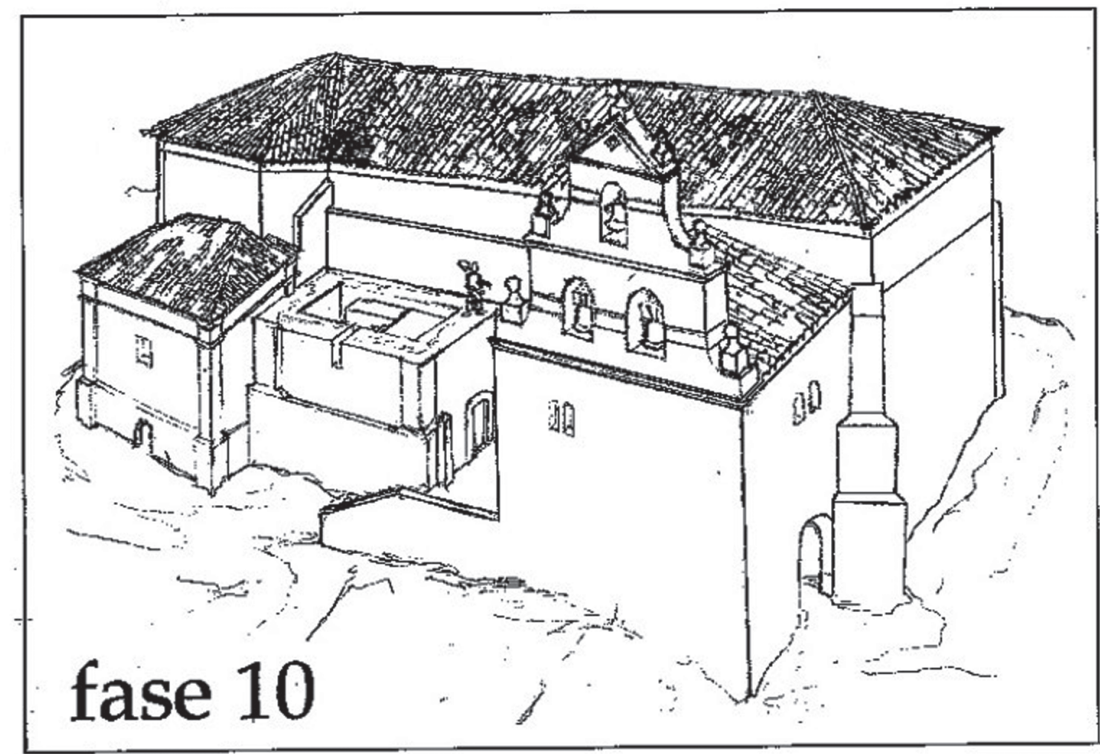

s. XIX.

Fig. 11. Reconstrucción figurada de las distintas etapas de la evolución constructiva de la iglesia (según Ibán Sánchez e Ismael García) 
ha crecido a partir de una muy modesta aula sin nada sobresaliente hasta el complejo edificio que hoy se nos presenta.

En la figura 11 se aprecia el progresivo crecimiento tanto en extensión como, sobre todo, en altura, del edificio a partir de la pequeña iglesia inicial. Este crecimiento en altura no se compensa, como debiera haber sido, con un reforzamiento de los muros inferiores, que se mantienen con sus espesores anteriores, lo que produce la debilidad de las partes altas, especialmente en el muro sur, el que conserva los tramos inferiores más antiguos.

\section{Construcción}

La fábrica es de piedra caliza y calcarenita, en su mayor parte de sillería bien trabajada aunque con sillares de pequeño tamaño - excepto en la sacristía一, procedentes muy probablemente de la parte alta del roquedo del lado sur. Los muros construidos con esa piedra están compuestos por dos hojas de sillería en sus caras visibles y un relleno interior de calicanto con piedras de pequeño tamaño y formas angulosas, lo que hace suponer que en su mayor parte sean precisamente el material sobrante del trabajo de talla de los sillares. Los espesores de estos muros son muy variables en toda la iglesia, con valores entre los ochenta centímetros y el metro y medio, como corresponde a una construcción hecha en distintas fases.

Las bóvedas de la iglesia son también de piedra, pero en este caso se utiliza para los plementos el travertino, material más poroso y ligero que la caliza compacta generalmente empleada. Los nervios, por su parte, siguen siendo de la misma caliza, lo que es muestra de que los constructores medievales conocían perfectamente las necesidades de resistencia de los distintos elementos constructivos: poca resistencia y gran ligereza para los plementos, cuyas tensiones — concepto desconocido para ellos, en todo caso- no alcanzan altos valores, y gran resistencia con mayor peso para los nervios, en los que sí se alcanzan tensiones considerables.

Los tejados, por su parte, construidos con teja cerámica curva sobre entablado de chilla de poca consistencia, descansan en una estructura de madera de roble de factura tosca pero muy eficiente y bien adaptada a la geometría del edificio, constituida por un sistema de cabios en dirección de la pendiente, apoyados en correas horizontales y sujeto todo el conjunto por una serie de cerchas de tipo castellano, si bien modificadas en la traza del tirante inferior, peraltado en su centro para salvar la parte alta de los arcos perpiaños sobre los que se sitúan. En la cabecera, el sistema se complica un poco al introducirse una serie de puentes formados por grandes vigas y jabalcones que sirven para reducir las luces en que deben apoyar las cerchas.

\section{DIAGRAMA ESTRATIGRÁFICO Y COMPORTAMIENTO ESTRUCTURAL}

La lectura estratigráfica del edificio efectuada en el estudio arqueológico permite reconocer la historia cultural, es decir, la de las intervenciones humanas, pero respecto a la historia real que queremos contar adolece de dos problemas: el primero, soslayar los efectos de los agentes naturales, no introducirlos en el diagrama temporal como partícipes de pleno derecho; el segundo, medir el tiempo en función de esas intervenciones, considerando los lapsos entre cada dos de ellas como equivalentes, sea cual sea su duración natural, es decir, dando el mismo valor temporal a veinte años que a dos siglos si en esos tiempos no se ha producido obra alguna.

El estudio que hacemos en este artículo trata de construir esa secuencia completa, siguiendo un proceso en tres instancias: en primer lugar, se hace una revisión gráfica de la correlación entre las fases constructivas y las lesiones y deformaciones padecidas por el edificio; a partir de estos diagramas, se hace una nueva narración del proceso histórico interrelacionando las secuencias de ambos procesos, las etapas constructivas y los procesos de degradación estructural; en el tercer punto, se esquematiza el proceso en una propuesta de diagrama que integra las dos secuencias en un solo proceso.

\section{A. Superposición de dibujos de etapas, lesiones y deformaciones}

$\mathrm{Al}$ entender que las lesiones y deformaciones del edificio son efecto de su evolución natural y son, en definitiva, la traza de esta evolución que estamos buscando, deberemos ponerla en relación con la traza que en forma de secuencia estratigráfica hemos venido a obtener en el estudio arqueológico. La superposición del dibujo de las etapas constructivas con el de los daños estructurales permitirá apreciar la relación fisica entre ambas, su entrecruce sobre la materia construida del edificio. Se hace esa superposición trabajando en los cuatro alzados del edificio y describiendo el proceso sobre ellos y sobre los distintos cuerpos de fábrica de la iglesia, esquemáticamente descritos en el apartado anterior.

\section{A1. Alzado norte}

En la figura 12 se aprecia que el cuerpo de la sacristía, izquierda, presenta tres grandes cortes verticales que separan a las esquinas del tramo central y cortan a éste en dos mita- 


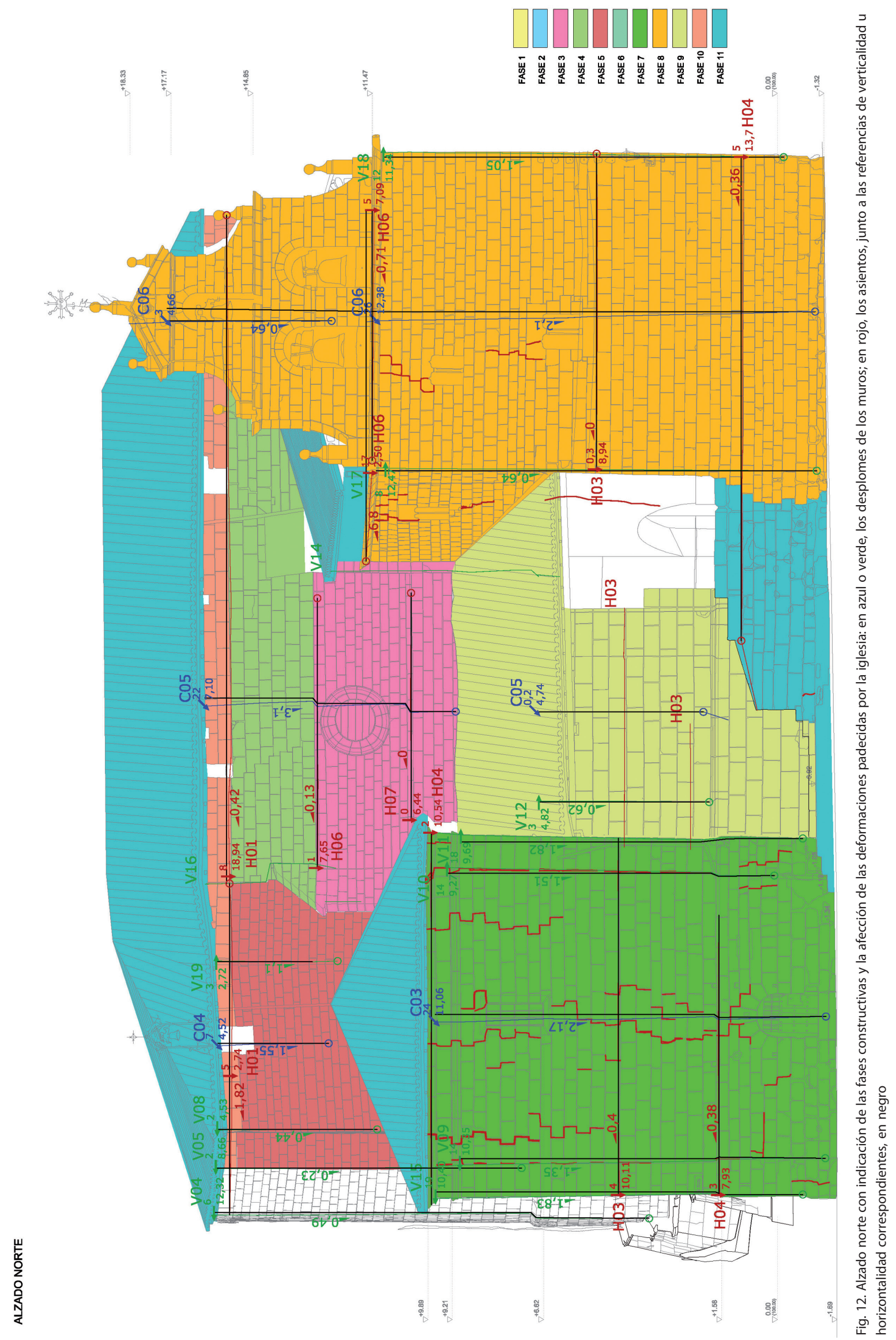


des, todo un sistema de desgajamiento del muro provocado por los empujes de la bóveda interior — que hoy ha desaparecido-y el asiento progresivo y no uniforme del terreno debido a la distribución no homogénea de las tensiones provocadas por los muros - excéntricas debido a los empujes de la bóveda - y a la distinta consistencia del terreno en cada zona. Por el contrario, la inexistencia de bóvedas en la casa rectoral, derecha, ha permitido que su muro norte se mantenga prácticamente de una pieza y se hayan inclinado hacia el oeste y hacia el norte de manera homogénea, si bien con una magnitud de giros mayor que la presente en la sacristía. El tramo central, la torre inacabada, muestra también un ligero desplome hacia el lado norte, debido al asiento del terreno en esta parte. Por su parte, la parte visible de la iglesia muestra, como en el muro sur, que los muros más modernos y más altos han padecido mayores giros que los que están bajo ellos, señal de que la mayor parte de esos desplomes se debe al empuje insuficientemente contrarrestado de las bóvedas. Los perfiles verticales muestran claramente todos estos desplomes y giros provocados por el asiento del terreno en el lado norte, con distintas intensidades según las distintas zonas.

Las deformaciones y lesiones estudiadas en el cuerpo de la Sacristía presentan una prácticamente completa simetría respecto al eje central de la fachada, lo que viene a indicar una evolución continua de su avance, sin soluciones de continuidad detectables. Al tratarse además de un cuerpo construido todo él en la misma etapa histórica, podemos seguramente establecer que esa evolución se viene produciendo desde el primer momento de la construcción, pues toda ella pesó y empujó desde el primer momento. Solamente la pérdida de la bóveda interior puede haber ralentizado el avance de las deformaciones, pero tampoco podemos asegurarlo porque no encontramos discontinuidades en ellas que podamos relacionar con la pérdida de la bóveda.

El caso es distinto en el análisis de la casa rectoral y su espadaña. La existencia aquí de dos fases constructivas distintas, la de la casa a finales del siglo XV y la de la espadaña en el XVIII, tiene un reflejo claro en la diferencia de inclinaciones alcanzadas por cada tramo de su muro norte. En efecto, la pendiente en la casa rectoral es de $2,1 \mathrm{~cm} / \mathrm{m}$, y en la espadaña, de $1,4 \mathrm{~cm} / \mathrm{m}$, lo que viene a indicar que el proceso se inicia con la construcción de la casa, hasta alcanzar, en dos siglos, una pendiente de $0,7 \mathrm{~cm} /$ $\mathrm{m}$-diferencia entre las dos pendientes calculadas-, y se acelera ligeramente con la construcción de la espadaña, que añade peso al conjunto y provoca un desplome de 1,4 $\mathrm{cm} / \mathrm{m}$ en otros tres siglos.
Es interesante comparar los dos cuerpos de edificación siguiendo esta línea: la sacristía, construida en una fecha intermedia — siglo XVII-, presenta una pendiente casi igual que la de la casa rectoral, de $2,16 \mathrm{~cm} / \mathrm{m}$, lo que admite dos explicaciones distintas, aunque no excluyentes: o bien se debe al empuje de la bóveda, que aumenta los giros al descentrar e inclinar las cargas en el terreno, o bien se debe a que el terreno es más compresible en esa zona. También interesa destacar esa progresividad del fenómeno del asiento, manifiesta en las diferencias observadas en la casa rectoral. Si se tratara de un asiento brusco producido por un descalce puntual del cuerpo edificado - por ejemplo al trazar la calle o, lo que sucede en muchas ocasiones, al introducirse tráfico rodado con sus dañinas vibraciones-, afectaría por igual a los dos tramos de edificación. Pero al apreciarse esa diferencia, podemos afirmar que se debe a un fenómeno de asiento progresivo del terreno, conclusión ésta que se sostendrá en más observaciones, como veremos.

Abundando en lo mismo, se puede entender que ese proceso progresivo ha afectado mínimamente a la torre inacabada, obra del final del siglo XVIII que presenta una pendiente de $0,2 \mathrm{~cm} / \mathrm{m}$, mucho menor que las anteriores tanto por el menor periodo de asentamiento padecido como por su mucho menor peso $\mathrm{y}$, sobre todo, por la distribución más amplia en el cimiento de este peso, respecto a las de sacristía y casa rectoral, más concentrada al tratarse de muros más delgados y más altos que producen unas más altas tensiones sobre el terreno y, por tanto, una mayor compresión y asiento.

En cuanto a la iglesia propiamente dicha, cabe ver en los giros de la cabecera, tan claramente simétricos y ordenados con respecto a su propia forma y a los empujes de su bóveda, la misma evolución temporal, pero mucho más lenta. Puesto que se trata de una construcción del siglo XVI y en la que se dan empujes y excentricidades de las cargas debidos a las bóvedas, sus pendientes hacia el norte deberían ser grandes, y sin embargo no podemos observar más que unos valores de entre $1,1 \mathrm{~cm} /$ m y $1,55 \mathrm{~cm} / \mathrm{m}$, menores que los de los otros cuerpos de edificación. Debemos atribuir esta menor magnitud de los desplomes a que el terreno se hace más firme según nos acercamos al roquedo del lado sur, si bien veremos más adelante que también se hace más débil hacia el oeste. Esta mayor dureza se deberá a que la composición del terreno en esta zona tiene unos estratos compresibles de menor espesor, aumentando éste a medida que nos separamos del roquedo y nos acercamos al cauce del río. 
En la nave, por su parte, se puede apreciar un fenómeno distinto: en el corte $\mathrm{C} 05$ se observa que la inclinación es mayor en el tramo más alto y más tardío de la construcción - recrecido con las bóvedas en fase IV-, lo que no se parece a lo ocurrido en las otras partes de la iglesia. Esto nos llevaría en primera instancia a atribuirlo precisamente a la falta de contrarresto eficaz contra los empujes de la bóveda por parte de los contrafuertes que flanquean este tramo del muro, sin perjuicio en todo caso de que el fenómeno de asiento del suelo también contribuya en parte al desplome global del muro. Sin embargo, como veremos, la recomposición de los empujes y deformaciones de las bóvedas obligada por la débil configuración del muro sur puede haber provocado una mayor descarga de esos empujes sobre este lado, aumentando su inclinación, segunda hipótesis que nos llevará a desconfiar cada vez más de la estabilidad global del edificio.

\section{A2. Alzado sur}

En el lado derecho de la figura 13, la cabecera muestra una progresiva apertura de sus muros en altura, con giros de las aristas y secciones de cada tramo cada vez mayores en dirección este - derecha—, lo que concuerda tanto con los empujes de las bóvedas como con el comportamiento del terreno ante las cargas excéntricas que éstos producen. En los dos tramos del aula la lectura es mucho más compleja. En primer lugar, respecto al sistema de grietas, éste muestra, por un lado, la formación de un arco de descarga sobre el tramo central, provocado seguramente por el asiento del cimiento de esa zona, y por otro lado, el desgajamiento y giro hacia el oeste de la esquina suroeste -izquierda - provocado por el empuje de las bóvedas insuficientemente contrarrestado al faltar un contrafuerte en la esquina debido a la sucesión de las fases históricas. Por otro lado, se muestran los perfiles de corte vertical en distintos tramos de la iglesia, y se aprecia en ellos que los giros son mayores en los tramos altos de los muros - en los tres cortes $\mathrm{C} 09, \mathrm{C} 10$ y $\mathrm{C} 11-$, si bien se inician desde el arranque inferior, todo lo cual indica que la causa es doble: ante el empuje de las bóvedas el muro más reciente y débil se deforma hacia el exterior más que el más antiguo y más fuerte de la parte baja; por otro lado, el asiento del tramo central hace que esos giros progresen más rápidamente en esta zona - mayor desplome, $55 \mathrm{~cm}$, en el corte $\mathrm{C} 10$ que en los cortes C09, $35 \mathrm{~cm}, \mathrm{y} \mathrm{C} 11,22 \mathrm{~cm}$ -

Dejando de lado la cabecera de la iglesia, que se explica en las fichas de los alzados norte y este, nos centramos en la compleja interacción entre las fases históricas y las lesiones y deformaciones de las fábricas presente en el muro de cierre de los dos tramos de la nave de la iglesia. En él podemos detectar la existencia de un notable descenso vertical de su tramo central, acompañado de un giro no menos notable en el contrafuerte intermedio. Este asiento afecta a todas las fases de la obra, pero se empieza a producir en el mismo momento de la construcción del muro, en fase I: la existencia de una hilada de regularización en el plano de apoyo sobre ella de la fase III viene a indicar que en el momento de la construcción de esta segunda ya se había producido ese descenso. Pero la ocurrencia de nuevos asientos que afectan a las fases III y IV en la misma zona viene a decirnos que el problema ha seguido activo hasta muy recientemente, y sin duda todavía ahora, como demuestra la pérdida parcial del plemento de la bóveda que descansa en este tramo del muro, pérdida consecuente con el cambio de correlación de empujes entre los lados norte y sur, originada por la debilidad de éste.

A este asiento se viene a añadir una reactivación producida por la secuencia de aperturas y cierres de los vanos de la escalera de acceso al coro hoy desaparecida. Al observar el vano del interior de la iglesia —el de arranque de esa escalera - se observa que el muro de mampostería que lo cierra ha sufrido un nuevo asiento que lo ha despegado de su dintel, donde aparece una grieta horizontal muy clara. Este descenso del muro sin duda ha de deberse a un fallo en el cimiento o el suelo bajo él, el mismo problema que ha venido padeciendo el muro en toda su historia (fig. 14).

Además, esa secuencia de reparaciones, en relación tanto con la eliminación de la escalera como con la reparación de los daños producidos por la voladura descontrolada de un peñasco caído contra el muro, ha sufrido - $-\mathrm{y}$ provocado- también su propio asiento, apreciable en la pérdida de horizontalidad de la hilada de lajas de piedra bajo la que arrancaba el tejadillo de la escalera desaparecida.

Todo ello viene a pedir una explicación que en este caso no puede atribuirse a la composición general del terreno sino, en todo caso, a un fallo local de éste o, más probablemente, a una deficiencia en la ejecución de la estructura de cimentación, quizá apoyando en estructuras anteriores o rellenos antrópicos no consolidados, dado que nos encontramos precisamente en la parte de evolución constructiva más antigua. $\mathrm{Y}$ en este caso, lo necesario para salir de dudas será la excavación arqueológica completa del espacio entre la iglesia y el roquedo, si bien esto no desdice de la conclusión ya explicada sobre la debilidad global del muro y sus efectos sobre las bóvedas, ya parcialmente destruidas. 


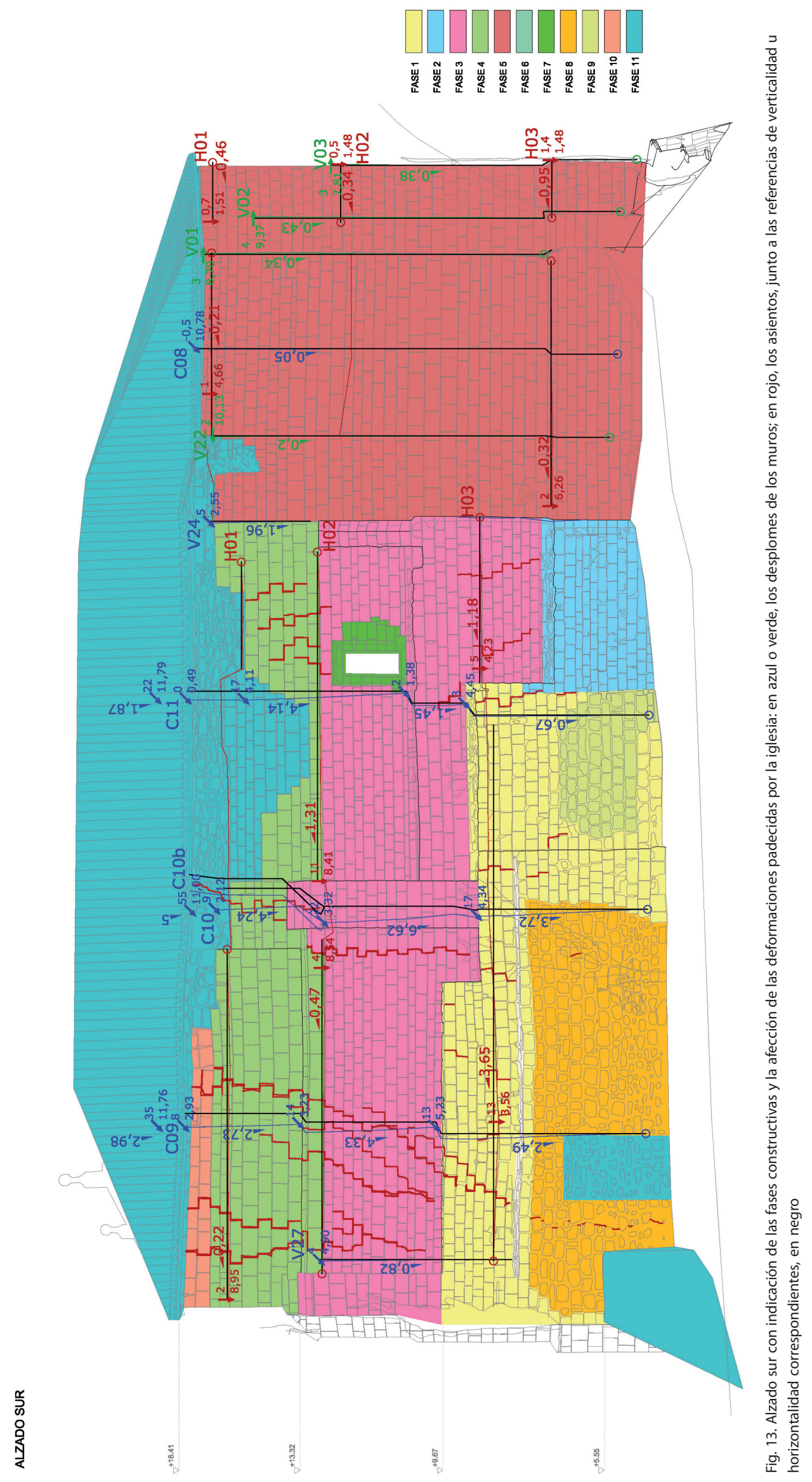




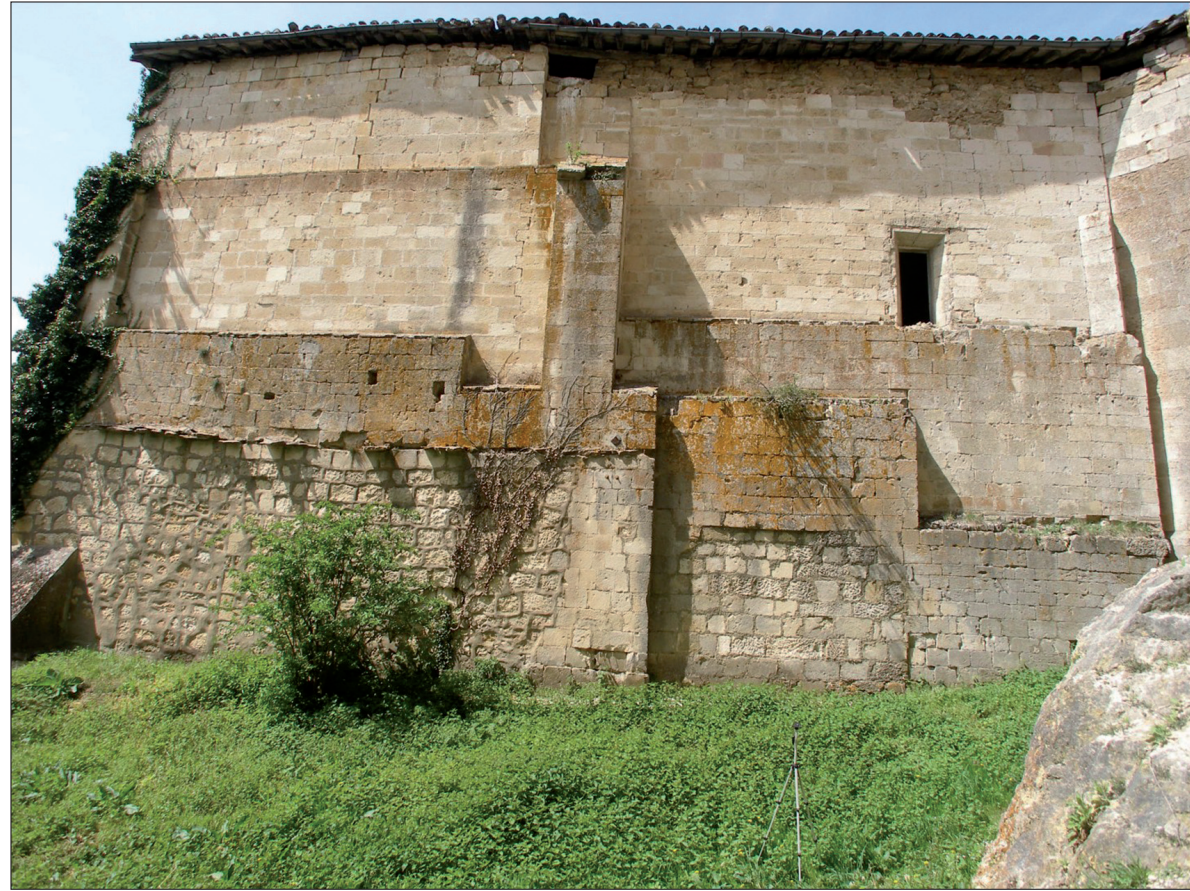

Fig. 14. Detalle de las fábricas en el alzado sur del aula de la iglesia. Se aprecian los desplomes del muro, formación de grietas y alabeos de los planos provocados por el giro del contrafuerte central. A la izquierda de éste se aprecian las hiladas de regularización que han sufrido posteriores asientos. Tanto en la esquina oeste -izquierda - como en el tramo central y en el rincón con el quiebro de la cabecera, apoyos B1, B2 y B3 respectivamente, se aprecia cómo los refuerzos mediante contrafuertes sobresalientes del muro tienen poca entidad porque se encuentran limitados por su apoyo sobre el muro inferior más antiguo, con lo que su eficacia estructural queda muy mermada
En cuanto a los desplomes que padece este muro sur, la tendencia se invierte respecto a la observada en los muros oeste y norte, pues aquí son mayores los desplomes de las fases inferiores. Si seguimos el corte C09 nos encontramos con inclinaciones sucesivas de $2,5 \mathrm{~cm} / \mathrm{m}$ en la fase I, $4,3 \mathrm{~cm} / \mathrm{m}$ en la fase III y $2,7 \mathrm{~cm} / \mathrm{m}$ en la fase IV, la correspondiente a la construcción de las bóvedas; y si seguimos el corte $\mathrm{C} 10$, esas mismas inclinaciones son de $3,7 \mathrm{~cm} / \mathrm{m}$ en fase I, $6,6 \mathrm{~cm} / \mathrm{m}$ en fase III y $4,2 \mathrm{~cm} / \mathrm{m}$ en fase IV. Esto viene a indicar que cuando se amplía la iglesia en altura para echar las bóvedas el muro ya está notablemente desplomado - la diferencia de pendientes sería de $1,5 \mathrm{~cm} / \mathrm{m}$ o de $2,4 \mathrm{~cm} / \mathrm{m}$, supuesto que se puedan restar linealmente-, tanto en la fase inferior como en la intermedia - I y III - y el recrecido de fase IV sufriría después un desplome con dos componentes, la del aumento de la inclinación y asiento general debida al problema del cimiento y la de la apertura debida al empuje de las bóvedas, que si en los lados norte y oeste no tenían suficiente contrarresto con los grandes estribos que allí hay, en este lado todavía lo tienen peor porque esos estribos tienen un tamaño mucho más reducido — de hecho inexistente en las partes bajas del muro- .

\section{A3. Alzado este}

En la figura 15 se aprecia la apertura en abanico de los distintos tramos de muro de cabecera de la iglesia, a partir de su arranque en el terreno, acompañada del corte vertical en su tramo central, provocados ambos daños por los empujes radiales de la bóveda estrellada de su interior. Sin embargo, también se comprueba que los giros no son simétricos respecto al eje de la iglesia, sino que tienen una clara componente en dirección norte, ladera abajo, correspondiente a la mayor compresibilidad del terreno según nos acercamos al río, situado al norte, derecha de la ilustración, y nos alejamos de la roca, al sur y a la izquierda. Este mayor asiento es claro en la sacristía, donde se produce un desgajamiento del muro en su tramo central y respecto a sus pilastras de esquina, siempre creciente de abajo arriba, además de un despegue claro respecto a la cabecera, apreciable en la grieta que separa los dos cuerpos de fábrica en su arista de contacto.

Respecto a la cabecera de la iglesia vale decir lo anteriormente explicado para su alzado norte: su evolución en el tiempo parece continua y lenta desde su construcción, pues los desplomes y grietas afectan a todo el conjunto y en toda su altura de manera uniforme. Los desplomes son prácticamente constantes en cada arista y las grietas se abren y multiplican hacia la parte alta prácticamente desde la base del muro. Todo ello indica que el fenómeno tiene su origen principal en el asiento del terreno, aunque probablemente podamos considerar que los empujes laterales debidos a las bóvedas también contribuyen a los giros. En realidad, desde el análisis estructural se entiende que estos empujes son los esfuerzos que ha de resistir el suelo y que, en respuesta a ellos, éste se deforma 


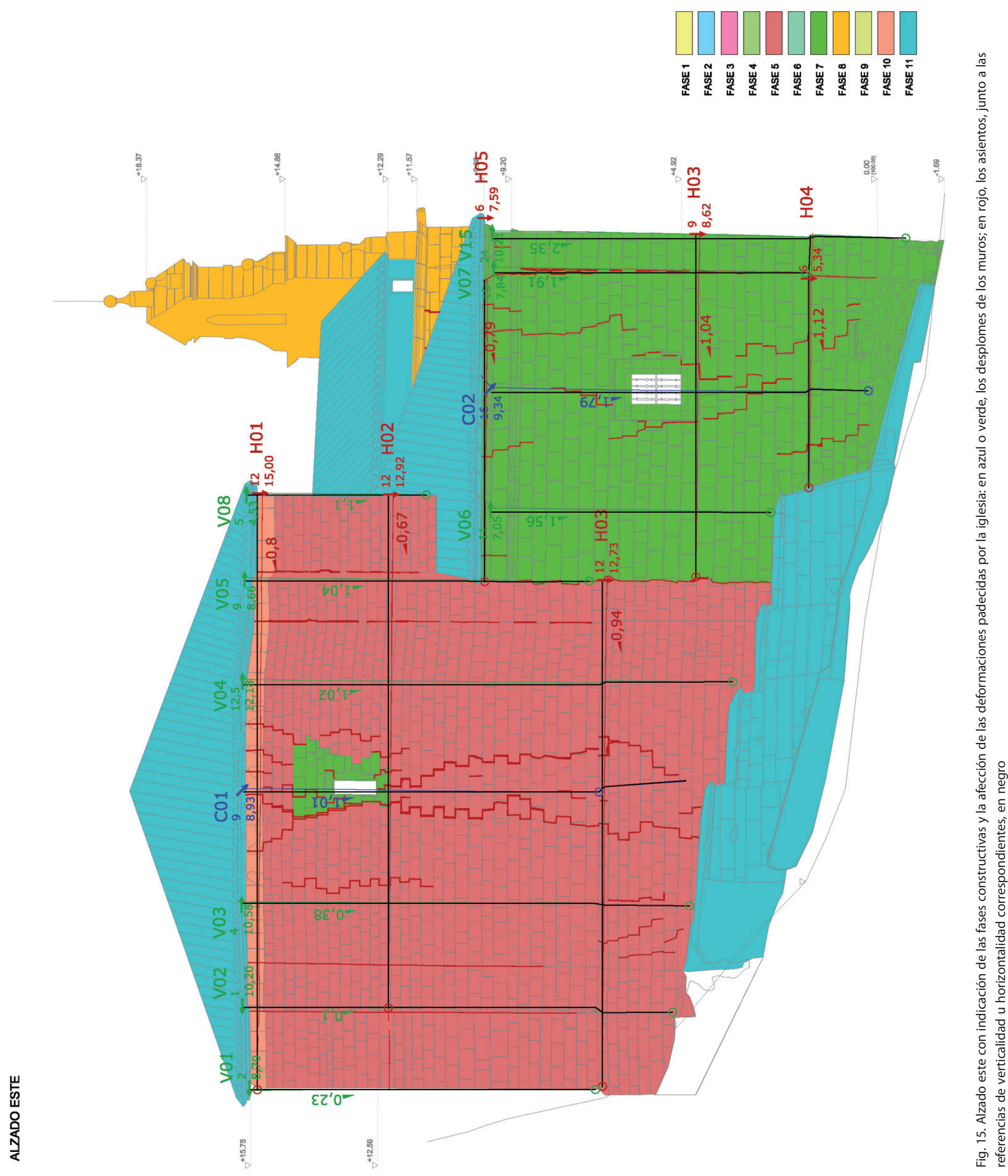




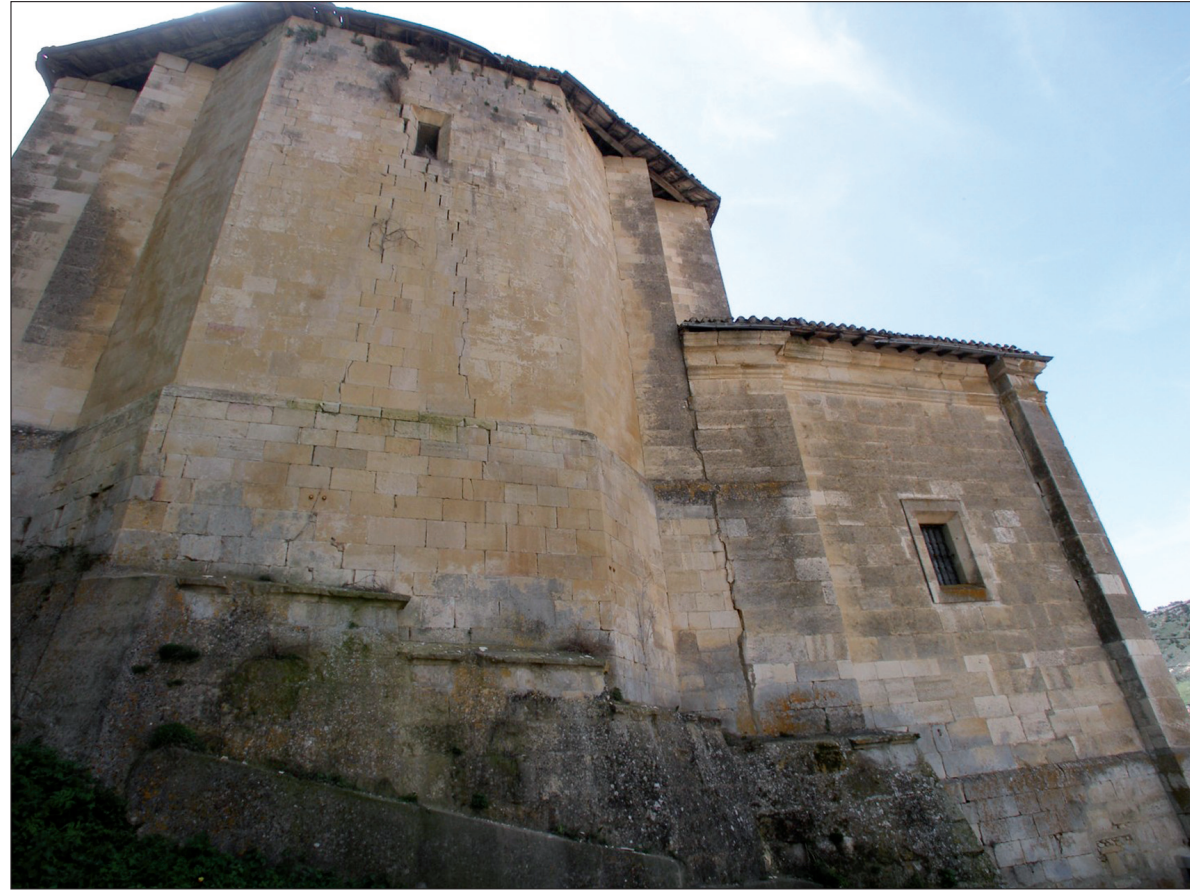

Fig. 16. Contacto entre la sacristía, a la derecha, y la cabecera de la iglesia, a la izquierda, con el mayor giro y despegue de aquélla respecto a la arista norte de ésta. Se aprecia claramente el sistema de grietas reflejado en la ilustración anterior y, especialmente, cómo la arista de contacto entre ambos cuerpos de fábrica, correspondientes a distintas fases históricas, se ha separado netamente, prácticamente independizando ambas construcciones. El hecho de que una construcción más tardía, de menor altura y con bóvedas más ligeras — la sacristía - haya sufrido un mayor giro hacia el lado norte no puede explicarse más que como consecuencia del aumento de la compresibilidad del terreno en esa dirección más en la zona donde es más compresible, es decir, ladera abajo. La composición estratigráfica de este suelo contiene un nivel arcilloso o limoso, y por tanto compresible, cuyo espesor aumenta según descendemos hacia el río desde el roquedo. Una ampliación del estudio geotécnico debe confirmar este dato en cuanto a los espesores de los distintos estratos, si bien no en cuanto a la existencia de ese estrato compresible, ya detectado por el estudio efectuado. Junto al roquedo debe casi desaparecer, y bajo la sacristía y la casa rectoral debe tener un espesor ya considerable, puesto que los asientos y giros se amplifican enormemente bajo los muros del lado norte.

En la sacristía, por tanto, se viene a apreciar, desde este lado, el mismo fenómeno observado ya en el lado norte: giro hacia el exterior de todas las aristas y muros, debido a esa combinación de esfuerzos horizontales y compresibilidad creciente del suelo hacia el norte y hacia el oeste. En el contacto entre la cabecera y la sacristía, es decir, entre las fases correspondientes a los siglos XVI y XVII, se aprecia que la sacristía se ha despegado de la esquina norte de la cabecera. Esto concuerda con lo antes explicado: el mayor asiento y giro del cuerpo más al norte — la sacristía- deja atrás al cuerpo más meridional —el sur-, a pesar de llevar menos tiempo construido - lo que podría haber significado que este último estuviera más inclinado-. Es lógico suponer que al construir la sacristía se hace una trabazón de sus sillares con los de la cabecera preexistente, lo que de hecho se observa perfectamente en la arista de contacto, en la que se han roto parcialmente los sillares de esquina de la iglesia para encajar los de la sacristía. En ese momento, la sacristía se construiría aplomada y en perfecto contacto con la cabecera, pero ahora se encuentra inclinada y despegada, lo que viene a indicar claramente que su evolución es más rápida que la de la propia iglesia, algo sólo atribuible al problema de la compresibilidad del terreno, ya que, como tal construcción, la sacristía es más baja, más ligera y con menores empujes que la cabecera, además de más tardía. Todo esto viene a reforzar la conclusión de que es la composición del terreno la responsable de las mayores deformaciones y lesiones que padece el edificio (fig. 16).

\section{A4. Alzado oeste}

En la parte derecha del dibujo de la figura 17, se aprecia el conjunto de grietas que cortan el hastial occidental de la iglesia desde su arranque y en toda su altura, provocadas tanto por el empuje interior de las bóvedas como por el asiento diferencial del lado norte con el sur. En el cuerpo adosado de la casa rectoral se aprecia el desgajamiento respecto al cuerpo de la iglesia y el giro del conjunto hacia el lado norte, provocado también por el mayor asiento del terreno al norte de la iglesia.

Lo que se observa en este lado de la iglesia viene a tener también una interpretación relativamente sencilla y paralela a la anterior. En el hastial occidental de la iglesia se aprecia que las grietas y desplomes afectan a todo el 


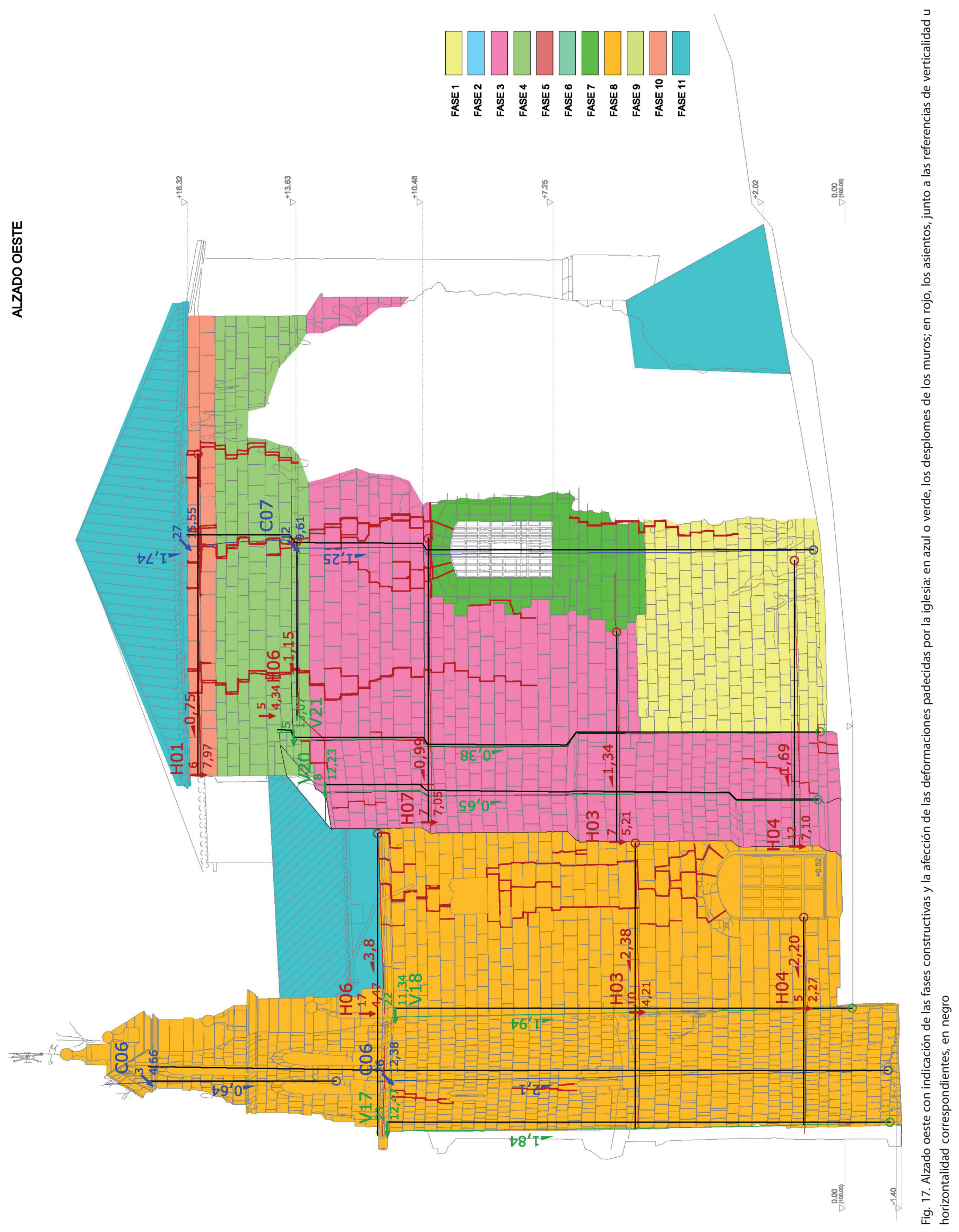




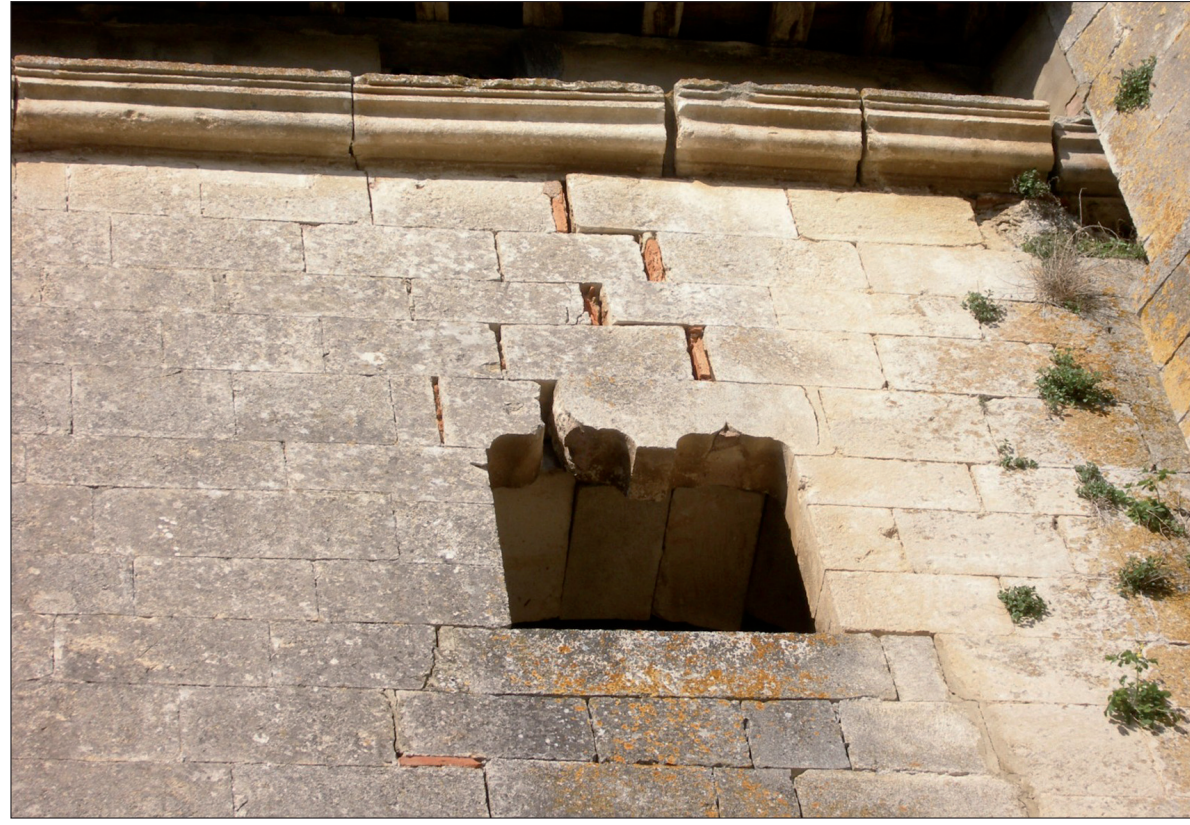

Fig. 18. Detalle de la secuencia de lesiones y reparaciones en el muro oeste de la casa rectoral, junto al contrafuerte noroeste de la iglesia. Se aprecia la inicial apertura reparada con la inserción de ladrillos de canto que, a su vez, han vuelto a separarse de los sillares de la fábrica. En el dintel fracturado se aprecia la intensidad del desplazamiento de una parte de la fábrica con respecto a la otra, casi suficiente para arrancar el gran cargadero de su empotramiento en el muro conjunto, desde la base hasta la cabecera del muro, si bien se puede observar un mayor desplome y apertura de grietas en la fase IV, correspondiente a la construcción de las bóvedas. Aquí como en el lado sur, por tanto, se presentan tanto el fenómeno de asiento y giro progresivos debidos al suelo como la apertura de los muros en su parte alta debida a las bóvedas, fenómenos ambos mutuamente dependientes. Y el argumento que lo explica es el mismo: al ser de construcción más reciente, la fase superior debería haber padecido un menor desplome que las partes más bajas y anteriores si todo se debiera al asiento del terreno. Al presentar esta última fase un mayor desplome que las inferiores, su movimiento debe atribuirse a otras causas, y no podemos encontrar otra que la de un contrarresto ineficiente de los empujes de las bóvedas.

En cuanto a la casa rectoral, también presenta un desplome de sus muros mayor que el de la propia iglesia. Mientras ésta tiene una pendiente de $0,65 \mathrm{~cm} / \mathrm{m}$ en el contrafuerte noroeste — su parte más inclinada—, aquélla se inclina $1,94 \mathrm{~cm} / \mathrm{m}$ en su arista noroeste. Por fuerza, esta diferencia de desplomes debería también manifestarse en el contacto entre ambos cuerpos, pues el de la casa rectoral es más moderno y sin embargo está más inclinado, como en el caso de la sacristía y la cabecera explicado más arriba. Y efectivamente así sucede, pero la separación de los cuerpos edificados no se produce en el contacto entre ambos sino más al norte —a la izquierda_- en la enorme grieta que corta al muro oeste de la casa rectoral a través de sus ventanas y puertas, lo que sin duda se debe a que todo ese tramo de muro viene a estar apoyado en la jamba sur de la puerta, cuyo cimiento es el mismo que el del contrafuerte de la iglesia, pues no hay sitio para más. Así, se repite exactamente el fenómeno del lado este: la edificación más moderna y con menores altura y empujes laterales está más inclinada que la más antigua, alta y abovedada, lo que no tiene otra explicación plausible que la de una diferente evolución del asiento en el terreno, nuevamente relacionada con la variación de los espesores de los distintos estratos compresibles según nos alejamos de la roca y acercamos al río.

Por otro lado esa grieta de separación entre los dos cuerpos no se acaba de estabilizar, pues, reparada ya al menos en dos ocasiones — con ladrillos la primera y con mortero de cemento la segunda-, ha vuelto a abrirse recientemente. Esta microsecuencia observada en la reparación y reapertura de la grieta se presenta también en las grietas de la sacristía, y viene a significar que el proceso de asiento progresivo sigue evolucionando, no se ha detenido hasta ahora y, por tanto, no podemos asegurar que no vaya a ir a más (fig. 18).

La medición de las grietas efectuada, sin embargo, al haberse realizado sólo durante un breve periodo de un año y al haberse situado los puntos de medición en las partes bajas de las grietas consideradas — sencillamente por ser más accesibles - no nos puede decir nada al respecto. Lo primero, porque ese período es demasiado corto para poder apreciar el retorno o progreso de las deformaciones a su punto de partida - para lo cual es necesario un período mínimo de observación de tres o cuatro años-; y lo segundo porque la magnitud de los movimientos en las 


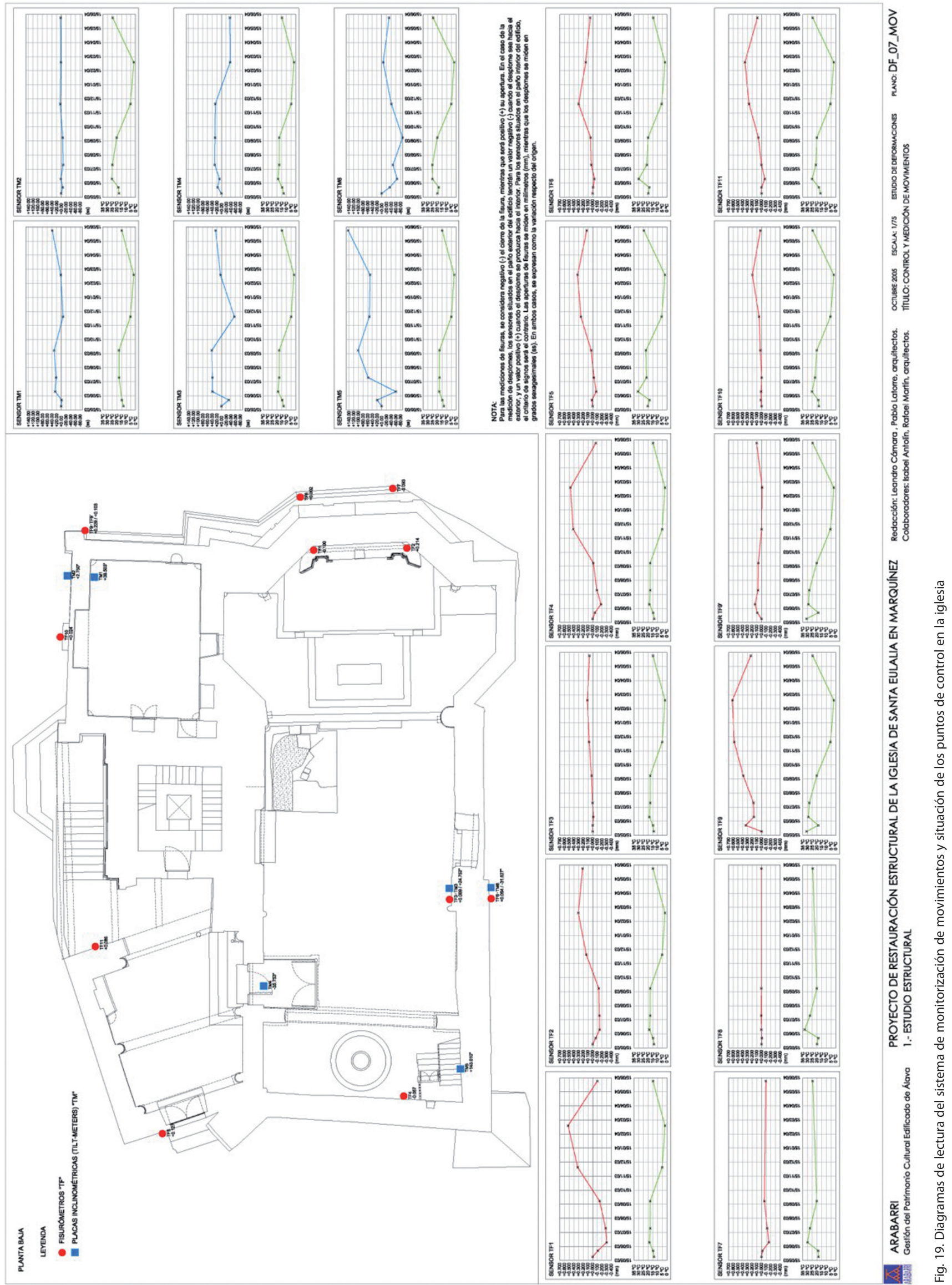


partes bajas de los muros, donde las grietas son muy pequeñas, resulta casi inapreciable, siendo necesario siempre disponer estos equipos en las partes altas de las grietas o de los muros, donde los movimientos tienen mayores rangos, son más fáciles de detectar y aportan más datos sobre sus direcciones y amplitudes (fig. 19).

\section{B. Etapas de obra, cuerpos de fábrica y evolución de los daños}

Como segunda aproximación para que la traza final que buscamos refleje el proceso completo de la evolución del edificio hacemos una descripción de éste poniendo en relación las etapas de obra y la evolución de los daños que les afectan, señalándolos en cada cuerpo de edificación y por cada fase, frente a la versión anterior en la que se explicaban las relaciones directas entre ambas presentes en cada muro de la iglesia.

\section{B1. Nave}

Fase I: aparentemente, en esta fase empiezan ya a producirse asientos en el muro sur —único resto conservado de ese momento-, debidos seguramente a una deficiente construcción de su cimiento o al apoyo de éste en rellenos o restos constructivos anteriores inconsistentes. No parece que este problema tenga su origen en la incosistencia del terreno, pues aun en el caso de encontrarnos con un lentejón compresible en esta zona, la escasa altura y peso de la estructura (ver fig. 11) seguramente no llegaría a provocar mayores deformaciones del terreno.

Fase II: la ampliación de la iglesia hacia el este en esta fase no presenta graves daños, ni procedentes de su momento de construcción ni posteriores. Pero en todo caso, esto es poco significativo dada la escasa entidad de los restos que se conservan.

Fase III: la enorme ampliación en altura de la iglesia, casi duplicando su volumen, no parece acusar tampoco otros daños propios que los que le vienen dados por la deficiente construcción del cimiento de fase I. Es decir, se mantiene la evolución del asiento en el tramo central del muro sur y, a pesar de la regularización de la hilada de apoyo de esta fase III, se acusan tanto un ulterior asiento como un giro del muro, si bien éste no alcanza su mayor desarrollo hasta la fase siguiente.

Fase IV: en este momento se construyen las bóvedas y se vuelve a aumentar la altura de la nave, probablemente dentro del mismo plan de ampliación de la fase III. Seguramente ambas fases son más bien momentos de obra que etapas históricas, pues no parece posible cerrar las bóvedas sin contar con los muros que soportan sus arcos formeros. Con esta obra, los problemas de diversifican: de un lado, se mantiene el del asiento y giro del deficiente muro sur, lo que se manifiesta tanto en el incremento progresivo de los desplomes como en el descenso de las hiladas de esta fase, acompañando a las del momento anterior, que no paran; de otro lado, en el resto de la iglesia, muros norte y oeste, parece que el abovedamiento no recibe un contrarresto eficaz en los estribos y comienza a producir la apertura de los muros en todo el perímetro. La inclinación y apertura de toda la iglesia en su parte alta se debe por tanto a un asiento y giro desde la base de los muros norte y oeste y al empuje no contenido de las bóvedas, y tiene una evolución que sigue hasta ahora, como se manifiesta en que las grietas que dañan de forma generalizada a toda la bóveda vienen a afectar también a los últimos revestimientos que éstas recibieron, probablemente hacia mediados del siglo XX. Este es sin duda el mayor problema de la iglesia, pues afecta directamente a su parte más sensible, las bóvedas, y su evolución es constante, debida a los sucesivos ciclos anuales de dilatación y contracción del conjunto, al estado no completamente consolidado del terreno, que hace prever nuevos asientos, y a la ya excesivamente deformada geometría de las bóvedas que las hace cada vez menos capaces de soportar nuevas aperturas de sus apoyos, habiéndose ya perdido una parte de ellas recientemente.

Fases X y XI: en los recrecidos y reparaciones de la cabeza de los muros de la iglesia no se aprecia una evolución distinta de la que afecta a los muros inferiores. De hecho, su escasa entidad impide hacer mediciones suficientemente significativas e individualizables. Debemos entender que se comportan como esas partes bajas y se inclinan o descienden a la vez que ellas.

\section{B2. Cabecera}

Fase V: toda la cabecera pertenece a esta fase y, como ya hemos explicado, tiene una evolución continua de giro de las esquinas abriéndose en abanico y de asiento del conjunto hacia el lado norte. Parece que el movimiento es muy lento y su efecto en la estabilidad de la fábrica poco preocupante, si bien también parece que sigue su curso y no se ha detenido, nuevamente por efecto de la progresiva consolidación del terreno ante unas cargas y empujes, las de los muros y bóvedas, siempre presentes.

\section{B3. Bóvedas}

Fase III-IV (aula): el proceso descrito de empuje de las bóvedas y apertura subsiguiente de los muros y contrafuertes en que descansan ha venido a provocar la expansión de 
sus plementos y el requiebro de algunos de sus arcos, hasta el punto de que aquéllos han perdido prácticamente su compresión interna, quedando sueltos, en riesgo de caída generalizada — ya se ha perdido de hecho parte de una bóveda- y, sobre todo, descansando completamente en los nervios, pues su falta de continuidad interna impide que trabajen como una cáscara comprimida, forma habitual de resistencia supuesta para los plementos de las bóvedas. Los nervios por su parte han sufrido una pérdida de curvatura generalizada, con esos mismos requiebros manifiestos en algunos de ellos, y con la consecuente sobrecompresión de la cara intradosal de los nervios quebrados que ha provocado ya la pérdida de parte de su sección resistente, también como es habitual en las nervaduras de estas bóvedas. La suma de la pérdida de capacidad portante debida al cambio de curvatura más el sobrepeso de los plementos sueltos más el sobreesfuerzo puntual en las zonas de quiebro de sus curvaturas provoca una notable precariedad estructural en los nervios que podría llegar a arruinarlos completamente. Todo este proceso es continuo e irreversible si no le ponemos remedio con una reparación; se inició en la propia construcción de las bóvedas y no se ha detenido en ningún momento, pues se debe a un deficiente contrarresto que tampoco se ha solucionado, sino que ha ido empeorando al aumentar la deformación de los muros debida al asiento en el terreno.

Fase V (cabecera): las bóvedas de esta fase no tienen el mismo problema. En primer lugar, la estructura de los muros en que apoyan es muy eficaz, con todos sus quiebros y muros diagonales que sí aportan un correcto contrarresto a los empujes; y en segundo lugar, la sobreabundancia de nervios y el pequeño tamaño de los plementos entre ellos hace que los esfuerzos se encuentren muy distribuidos y no alcancen nunca altos valores. La apertura que sin duda han sufrido estas bóvedas se debe a la apertura progresiva y giro desde la base del conjunto de esos muros por causa del asiento del terreno, movimiento que si bien tampoco se ha detenido, lleva una velocidad muy pequeña y no debe preocuparnos.

\section{B4. Casa rectoral y espadaña}

Fase VIII: si bien creemos que la casa rectoral pertenece a una etapa anterior, no identificada pero situada a finales del siglo $\mathrm{XV}$, en todo caso tras la construcción de las bóvedas en fase IV - por motivos estratigráficos- $-\mathrm{y}$ antes de la de la cabecera en fase $\mathrm{V}$ - esto por motivos cronotipológicos basados en el detalle de las ventanas geminadas, de las gárgolas y de las cornisas-, no podemos asegurarlo sin la documentación necesaria. Con todo, la observación de la diferencia de sus desplomes con los de la espadaña sobre ella —esta sí de fase VIII—, viene a abonar nuestra hipótesis. Como se ha dicho, el asiento progresivo del terreno afecta más a las partes más antiguas — la casa rectoral — y menos a las más modernas — la espadaña-, que tienen por tanto distintas inclinaciones. En todo caso, parece que este asiento y giro no se ha detenido todavía, debiéndose sin duda al asiento en el terreno y a la ya varias veces mencionada mayor compresibilidad global de éste en la zona norte, hacia el río.

\section{B5. Sacristía}

Fase VII: el proceso es el mismo que en el caso anterior, si bien en una sola fase. La sacristía asienta y gira a mayor velocidad que el resto de la iglesia y se separa de ella sin que podamos decir cuándo se detendrá, pues nuevamente se debe al asiento de un terreno que no parece haberse consolidado todavía suficientemente.

\section{B6. Conjunto del edificio}

En resumen, podemos concluir que son tres los problemas que ha padecido y sigue padeciendo la iglesia desde el momento de su construcción; en primer lugar, el más grave por ser el que evoluciona más rápidamente es la mala construcción del cimiento del muro sur, que ha provocado asientos, desajustes, reparaciones insuficientes y, últimamente, incluso la ruina de parte de una bóveda, todo dentro de un proceso que no se ha detenido ni lo hará hasta que podamos actuar correctamente sobre esa deficiencia del cimiento y sobre el propio muro sur reparando los daños sufridos hasta ahora; el segundo problema es el del insuficiente contrarresto de los empujes de las bóvedas en los muros y contrafuertes del cuerpo principal de la iglesia sobre el muro sur, puesto de manifiesto en los diagramas de cálculo (fig. 5) y cuya consecuencia es la apertura de aquéllas y su pérdida de cohesión y capacidad autoportante, en un proceso que también está activo si bien probablemente con una velocidad de desarrollo menor que la del problema anterior; por último, el tercer problema en evolución es el asiento de la zona norte y oeste del terreno, cuyo alcance y evolución no podremos determinar sin un estudio geotécnico detallado del suelo, pero que es sin duda un proceso también activo y que requerirá una intervención, siquiera sea sólo la de estudiar su origen y el ritmo de su avance para poder considerar que éste no pondrá en riesgo a la estructura en un plazo de tiempo razonable, ya que, por otro lado, consideramos que las intervenciones de recalce o refuerzo de cimientos vienen a ser a la larga más dañinas que las que inciden sobre la 
reparación de los daños observados, como las que se proponen más adelante.

\section{Discriminación diacrónica de las lesiones y deformaciones: periodos de actividad o reparación}

A partir de esta lectura superpuesta de unidades estratigráficas, etapas de obra y evolución de las lesiones podemos discriminar cuáles son las intersecciones entre ambas, de qué modo un daño ha afectado a unas u otras unidades y fases, según lo explicado, y hasta qué punto la intervención constructiva realizada en un determinado momento ha reparado un daño o, eventualmente, lo ha acentuado. El entretejido de los procesos permitirá conocer la velocidad a que se producen los distintos fenómenos y podrá servir para predecir el futuro comportamiento del conjunto y, sobre todo, valorar la precariedad o seguridad del equilibrio actual. Podremos establecer si un proceso de degradación estuvo activo entre tal y cual momentos históricos, o si lo está todavía, a qué velocidad evoluciona y si pone en riesgo la estabilidad del edificio; si las eventuales reparaciones históricas tuvieron el efecto buscado o si el deterioro estructural ha sido más intenso de lo que han podido remediar los que han tratado de conservar el edificio.

En primer lugar, reproducimos el diagrama estratigráfico obtenido en el estudio arqueológico del edificio, donde los intervalos carecen de duración —escala- - y sólo se atiende a la secuencia de las relaciones de anteroposterioridad entre las distintas unidades estratigráficas discriminadas.

En el diagrama canónico (fig. 20) se muestra la secuencia de las sucesivas fases constructivas, atribuyéndose a cada una de ellas el mismo valor temporal, ya que es la sucesión de las intervenciones constructivas la que interesa reseñar. La amplitud vertical de cada fase no se corresponde con su duración temporal sino que deriva únicamente del grafismo con el que se representan las unidades en sus celdas y las relaciones de anteroposterioridad entre ellas. Sin embargo, este sistema de representación es el generalmente aceptado para mostrar precisamente estas relaciones. Por otro lado, y también de modo canónico, todas las unidades tienen el mismo valor estratigráfico, sin tener en cuenta su importancia arquitectónica o su extensión constructiva.

A partir del diagrama, la secuencia conjunta que buscamos se refleja en un diagrama cronológico construido con la unidad de medida del tiempo natural, pero marcado por los hitos de la evolución artificial. Como quiera que los ritmos naturales varían en cada lugar y época, sólo la cronología artificial permite marcarlos y comprenderlos: no podemos saber la velocidad a la que el río socava el terreno a los pies del lado norte de la iglesia, pero su efecto sobre el edificio provoca obras de reparación en momentos concretos que podemos conocer por el estudio histórico, de modo que podemos evaluar el efecto que ese socavamiento ha tenido sobre la iglesia hasta ahora y la velocidad a la que se ha producido mediante la datación de las distintas intervenciones.

\section{C1. Representación en el diagrama}

En el diagrama (fig. 21) se mantienen, evidentemente, las relaciones estratigráficas entre las distintas unidades discriminadas por el análisis, si bien a éstas no se les da el mismo valor gráfico, grafiándose con mayor tamaño las que representan a los cuerpos de fábrica principales de cada fase, y con menor tamaño a los elementos menores de las mismas, y singularmente a las soluciones de continuidad que los limitan. Por otro lado, la escala vertical adoptada viene a representar el tiempo completo transcurrido desde el inicio de la construcción del edificio, y coloca cada fase a la altura cuya fecha aproximada exigiría. Las fechas dadas en el lado derecho deben entenderse, bien como datos veraces extraídos de libros de fábrica u otros documentos de obras, bien como aproximaciones basadas en una datación cronotipológica. En cuanto a la distribución en horizontal de las distintas columnas correspondientes a los distintos cuerpos de fábrica, entendemos que facilitan la lectura de qué fases entran en contacto -es decir en relación temporal- con cuáles en cada zona del edificio, lo que ayuda en la comprensión de los fenómenos físicos - estructurales en este caso- que se trata de analizar, pues éstos son siempre muy dependientes de su situación en el edificio y en relación con el terreno, lo que no tiene por qué ser cierto, en cambio, para las etapas históricas. Esta distribución permite y obliga a colocar las distintas fases de obra varias veces en el diagrama, pues mantienen relaciones estratigráficas en distintas partes del edificio, en los contactos entre distintos cuerpos de fábrica; para evitar la confusión que podría devenir de esta reiteración se han situado las distintas llamadas a cada fase a la misma altura del diagrama en cada columna correspondiente a cada cuerpo de fábrica. Por último, las trazas de los procesos de deterioro se han marcado en colores distintos para permitir su seguimiento a lo largo del tiempo representado en el diagrama, y se han relacionado con las distintas unidades estratigráficas haciendo una analogía con el criterio temporal con que se discriminan las relaciones entre éstas, es decir, marcando como "posterior a» su afectación a cada 


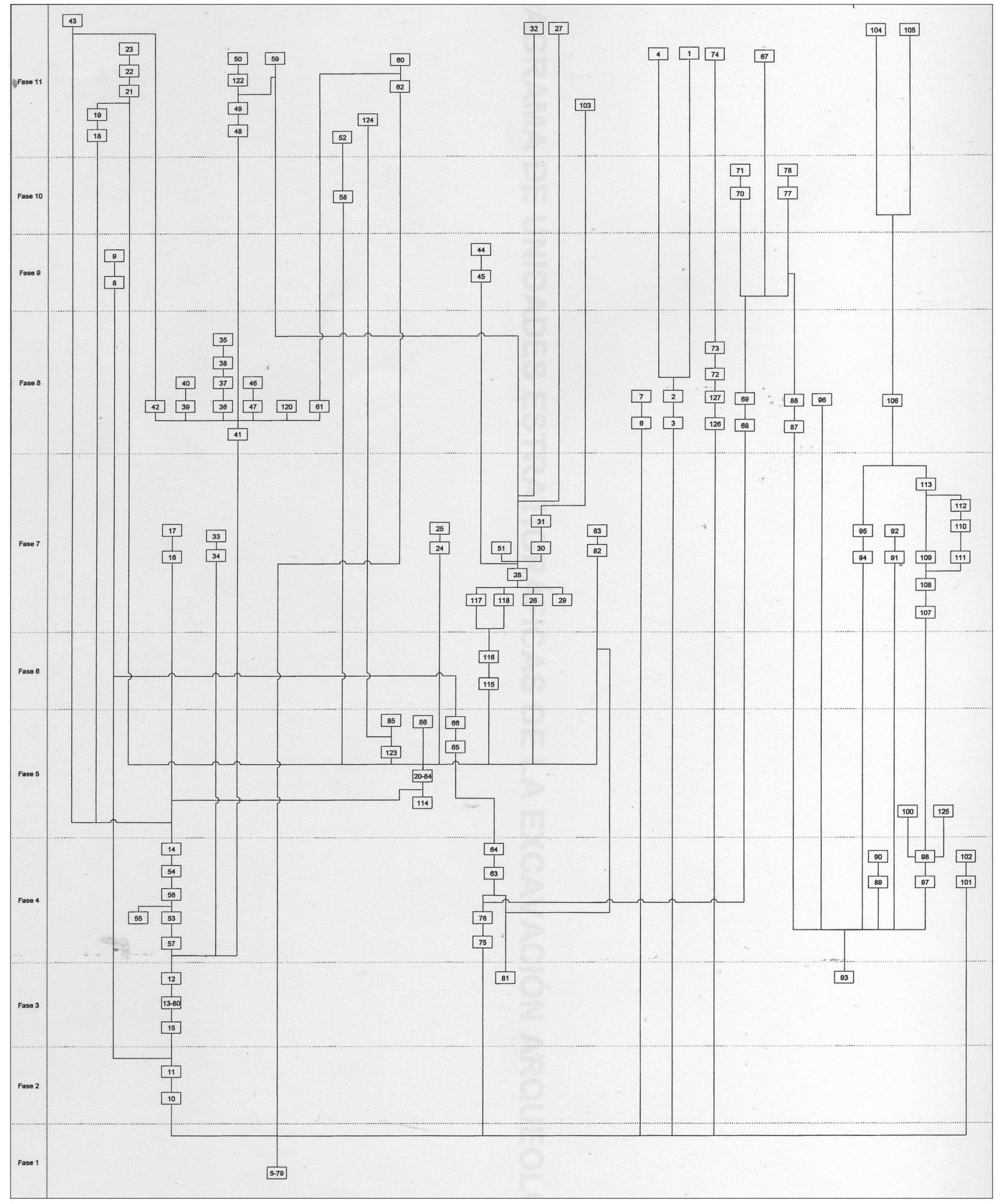

Fig. 20. Diagrama estratigráfico de unidades y etapas constructivas (según Iban Sánchez e Ismael García) 
unidad estratigráfica del diagrama. De este modo, los daños discurren lateralmente a las unidades estratigráficas según pasa el tiempo, y se ponen en contacto con éstas en relación de posterioridad cuando afectan a las fábricas que son estas unidades.

Representamos, por tanto, los procesos naturales como vectores que se extienden a lo largo del tiempo mientras son activos, habiendo aparecido sólo en el momento en que hay algún elemento constructivo al que puedan afectar. Ponemos esos vectores en relación diacrónica con las unidades estratigráficas afectadas: si el fenómeno daña a la unidad lo consideramos cronológicamente posterior; si tras una intervención el daño persiste, el vector seguirá avanzando; si la intervención cancela el daño la consideramos posterior a éste y entendemos que el vector queda interrumpido; y si lo acrecienta, consideramos que duplica el vector, pues aumenta la velocidad de su desarrollo. De este modo, el diagrama trata de resolver el problema de esa diferencia sustancial entre la falta de duración de las intervenciones, hechas de una vez por todas en un breve instante, y la duración constante de los movimientos y las degradaciones materiales.

El diagrama representa sólo las unidades y etapas de los cuatro alzados estudiados, por un lado, y los tres vectores de los movimientos detectados, a los que damos nombre para mostrarlos esquemáticamente. Hemos de decir que no se ha considerado la secuencia de degradación físico química de los materiales porque no es el caso en estudio, pero creemos que su representación diagramática sería muy similar a la que hacemos para la secuencia de los movimientos estructurales.

\section{C2. Asiento del terreno en el muro sur, AMS}

Con origen en la deficiente cimentación del tramo central del muro sur del aula de la iglesia, se manifiesta en y afecta a todo el muro sur al provocar distintos fenómenos de descarga de los pesos y empujes para adaptarse a la falta de apoyo que supone para el conjunto, con los sistemas de grietas y giros de los muros que se han descrito más arriba. Es un proceso no detenido, pues ninguna unidad estratigráfica lo cancela en ningún momento, sino todo lo contrario, afecta hasta a las de construcción más reciente - las reparaciones de la cabeza del muro en fase X, con la construcción de las nuevas cubiertas durante el final del siglo XIX o el inicio del XX-.

\section{C3. Giro del muro sur hacia el exterior, GMS}

Con origen en la insuficiente sección constructiva del contrafuerte central de las bóvedas del aula — apoyo B2-
, afecta a los dos tramos del muro sur del aula, combinándose algunos de sus efectos con los del movimiento anterior. Se manifiesta en el giro hacia el exterior del muro sur, que alcanza su mayor inclinación justamente en ese punto de apoyo de las bóvedas, razón por la cual se distingue del fenómeno anterior: un asiento no implica un giro del muro salvo en presencia de empujes laterales, lo cual es nuestro caso. Es también un fenómeno activo, pues tampoco se ve cancelado por ninguna otra unidad estratigráfica, ya que también esa última fase $\mathrm{X}$ de reparación del muro ha adquirido su propia inclinación, difícilmente apreciable a simple vista pero bien patente en las mediciones topográficas. En los perfiles C09, C10 y C11 se aprecia que la cabeza del muro, que sin duda se rectificó al recrecerlo en esta fase, se encuentra sin embargo desplomado, lo cual no admite otra explicación que la del progreso continuo de este giro global.

\section{C4. Asiento del terreno hacia el norte y el oeste, ATN y ATO}

Con origen en el asiento progresivo del terreno debido a su composición no uniforme formada por estratos de distintos espesores y compresibilidades, es el proceso más lento pero más constante, que afecta a toda la iglesia y produce daños manifiestos en sus dos hastiales, este - cabecera- y oeste - pies-, y en los tres cuerpos adosados, casa rectoral, sacristía y torre inacabada, quedando sólo la fachada sur libre de sus efectos. Es también un proceso que parece no estar detenido, pues nuevamente ninguna etapa constructiva lo cancela ni deja de estar afectada por él, si bien en este caso no podemos apoyarnos en el comportamiento del recrecido de fase $\mathrm{X}$, ya que en la fachada norte éste acusa la inclinación del muro completo (perfil C05). De hecho, siguiendo con rigor el método elegido en este trabajo, podemos asegurar, basándonos en la deformación existente en las distintas fases de obra, que este movimiento ha seguido activo después de la construcción de la torre en fase IX, pues ésta acusa un leve desplome hacia el lado norte, pero no por cuánto tiempo desde entonces. Nos encontraríamos aquí en un punto indeterminado de la secuencia. De hecho, en dos puntos concretos, el recalce de la cabecera y la reparación del pretil de la escalinata de acceso en la fachada norte, ambos en fase XI, es decir recientemente, este movimiento no afecta a las unidades estratigráficas correspondientes, y pareciera que ambas se producen tras la detención de ese movimiento, o de su efecto sobre la fábrica, si bien esto puede ponerse en duda dada la lentitud con que se producen generalmente los asientos en el terreno y los consecuentes descensos o giros 


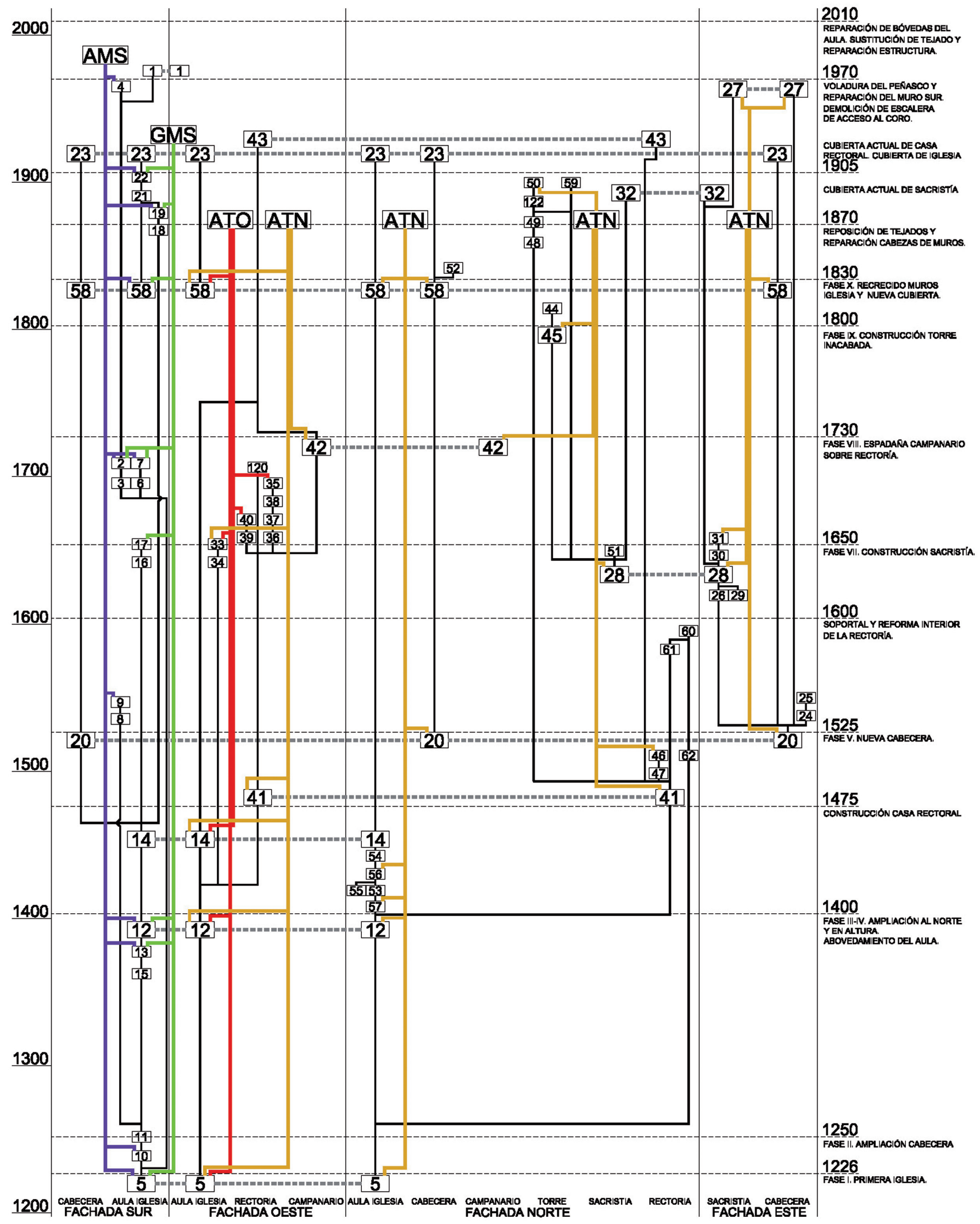

Fig. 21. Diagrama temporal de fases constructivas y daños estructurales tentativamente propuesto en este trabajo 
de los muros afectados, máxime cuando, como en este caso, se trata de las partes bajas de la fábrica, donde su amplitud es siempre menor que en las partes más altas.

\section{C5. Resultado del diagrama}

En conclusión, la revisión de la evolución de esos movimientos representados en el diagrama en relación con las fases constructivas y con las unidades estratigráficas da como resultado que los movimientos detectados a través de sus consecuentes grietas, desplomes y pérdidas de forma señalados en las figuras que acompañan este texto -una selección de las realizadas en el estudio estructural completo-, se encuentran activos y ponen en serio peligro la estabilidad global de la construcción.

El asiento en el terreno, ATN y ATO, tiene un desarrollo lento aunque inexorable, y no parece que vaya a provocar esa ruina por sí mismo, si bien fenómenos como el desplome de la fachada norte de la casa rectoral estén muy evolucionados y hagan que el centro de gravedad global de la fábrica se encuentre relativamente cerca de desequilibrarse, pues alcanza una magnitud de $26 \mathrm{~cm}$ en la parte alta de lo que se encuentra cerca de ser la tercera parte de un muro que tiene un espesor aproximado de $1 \mathrm{~m}$, punto en que nos encontraríamos en serio riesgo de inestabilidad global. La lenta evolución de este asiento es lo que nos permite no ver esto como un riesgo inmediato, pues debemos considerar que ese desplome es el resultado de seis siglos de avance de ese movimiento y, si el ritmo no se incrementa, como parece indicar la evolución de la espadaña, contamos con un perido de otros dos siglos antes de que se produzca ese desequilibrio.

Por su parte, los movimientos del muro sur, AMS y GMS, sí son claramente preocupantes y deben ser evitados mediante intervenciones de reparación en el muro sur. Su desarrollo parece más rápido que el del movimiento anterior, a juzgar por la magnitud de los daños que han provocado tanto en el propio muro como en las bóvedas. La reciente pérdida de parte del plemento de éstas es una señal clara de que estos movimientos no se encuentran ni mucho menos detenidos, lo que concuerda tanto con el resultado del diagrama como con las observaciones y cálculos estructurales realizados.

\section{PROGNOSIS}

Para terminar, el objetivo final de este estudio es la previsión del comportamiento futuro de la construcción. Como se decía al principio, un simple análisis estructural, incluso el más refinado basado en la mecánica de bloques y sus estados límite, tiende a considerar que los fenóme- nos se producen «ahora» y exigen una solución "ya», por lo que en general obtienen como conclusión una intervención de consolidación o refuerzo estructural que, en el mejor de los casos, modificará parcialmente al edificio y, en el peor, podrá dañarlo si al técnico interesado le da por emplear técnicas incompatibles con la construcción histórica o por desmontar ciertos elementos considerados «irrecuperables».

Por el contrario, el objetivo de este trabajo ha sido evitar esa visión «urgente» de los problemas, contemplarlos con la perspectiva del tiempo en que se han desarrollado para desde este nuevo punto de vista mirar hacia el futuro con una escala temporal bien calibrada.

En última instancia, este conocimiento del historial del edificio nos permite entrar en su vida de manera más consciente, sabiendo cuáles son sus tendencias naturales y discriminando cuáles de esos procesos suponen un riesgo cierto para la estructura, a la que no sólo habrían puesto cerca del colapso sino que seguirían tendiendo hacia él por no encontrarse detenidos todavía, en nuestro caso los movimientos del muro sur, nombrados AMS y GMS, y cuáles tienen un desarrollo más lento y de consecuencias menos inmediatas, los asientos en el terreno al norte y al oeste, nombrados ATN y ATO. Es decir, cuáles podrían exigir intervenciones estructurales urgentes, cuáles demandan reparaciones constructivas sencillas y cuáles sólo requieren un seguimiento atento de su evolución.

Las propuestas concretas de intervención se explican brevemente en el punto siguiente, pero aquí hay que decir que un criterio primordial de nuestra intervención en el edificio es el de tener en cuenta esos ritmos de evolución del edificio para tratar de mantenerlos tal cual son, limitando nuestra obra a dotar a la iglesia de nuevos márgenes para aceptarlos y sin pretender cortarlos en su avance mediante actuaciones violentas que no darían resultado positivo alguno. La seguridad de una estructura de fábrica no se obtiene mediante su refuerzo y rigidización sino mediante la mejora de su capacidad de adaptación a las variaciones de sus condiciones de contorno, sean éstas el asiento del terreno o la acción del viento y los ciclos térmicos, capacidad que se ve siempre muy desmejorada con las técnicas de consolidación más al uso ${ }^{11}$.

\footnotetext{
${ }^{11}$ Mastrodicasa, 1988, y Di Stefano, 1990, muestran todo el repertorio de soluciones de rigidización de una estructura de fábrica que se apoya en la supuesta incapacidad mecánica de éstas, basándose siempre en los resultados de un análisis elástico de su comportamiento que, en todo caso, no se demuestra para los casos prácticos mostrados. CROCI, 2001, da las herramientas prácticas para el conocimiento concreto de cada estructura y algunas soluciones aplicadas tras el diagnóstico correspondiente, sin duda con un criterio más prágmático y menos prejuicioso.
} 


\section{Propuesta de intervención}

Como conclusión podemos decir que la evolución del edificio parece tener dos vectores claramente peligrosos y otro de alcance y riesgo indeterminados por ahora.

En primer lugar, tanto el asiento del muro sur como la apertura de las bóvedas deben ser detenidos, para lo cual es necesaria la reparación de ambos: la del muro mediante la recolocación de las zonas gravemente dislocadas, la reparación de su cimiento y la consolidación interna de la fábrica; y la de las bóvedas mediante la corrección de las curvaturas de los nervios quebrados y la reparación constructiva de las grietas de los plementos para la recuperación de su compacidad y capacidad autoportante.

En este caso, se trata de acometer una consolidación estructural completa que incluirá, además de las reparaciones del muro y la bóveda dichas, el refuerzo de la esquina suroeste y del apoyo central de las bóvedas -puntos B1 y B2- mediante la inserción de dos contrafuertes construidos con fábrica de cantería, elementos que deben englobar la traza de los esfuerzos procedentes de las bóvedas que ahora se encuentran insuficientemente contrarrestados, según el cálculo efectuado (ver fig. 5). Estos contrafuertes deberán, por un lado, cimentarse adecuadamente para evitar que su posible posterior asiento aumente el problema de giro de las fábricas en lugar de reducirlo, y por otro, encontrar un sistema de contacto con la fábrica existente que evite que ambas se despeguen con ese inevitable asiento, mediante la introducción en su zona de contacto de cuñas pasivas —elementos adovelados- que se «activen» cuando se produzcan esos movimientos.

En cuanto a la reparación de las bóvedas, se trata de recuperar su consistencia perdida por tres vías complementarias: en primer lugar, la recolocación de algunos nervios, los que se encuentran quebrados sobre el apoyo B2 (ver fig. 4) mediante la elevación de las bóvedas con gatos hidráulicos y la recolocación de sus dovelas en una nueva curvatura adaptada a la situación real actual de los muros y los puntos de apoyo y arranque de los nervios, que se dan por irrecuperables en sus desplomes ya sucedidos; en segundo lugar, la reparación de esos nervios en las partes quebradas donde han perdido parte de su sección constructiva a causa de la concentración de tensiones en su fibra de intradós (ver fig. 4) mediante la inserción de injertos de piedra unidos a la masa principal del nervio con llaves o microcosidos y tales que repongan la sección constructiva completa del nervio y recuperen su capacidad resistente, si bien una vez más adaptada a la nueva geometría que ya han adoptado; y en tercer lugar, mediante el rejuntado en profundidad de las grietas de los plementos, mediante morteros y lechadas de cal, de manera que se recupere su continuidad física y se les permita trabajar nuevamente como cáscaras autoportantes, dejando así de descargar su peso directamente sobre los nervios como ahora hacen.

En segundo lugar, el fenómeno del asiento ladera abajo, hacia el norte y el oeste, parece ir lento y darnos más márgenes, y esto en el supuesto de que las últimas actuaciones urbanas en el entorno de la iglesia —asfaltado de la calle y hormigonado del cauce del río- no hayan ya detenido el proceso, lo que en todo caso no podríamos detectar con los estudios hechos en este informe por el poco tiempo transcurrido desde su realización; en este aspecto, no trataremos de ir por tanto a la génesis del problema sino sólo a sus efectos, procediendo a reparar las lesiones sufridas por los muros y eventualmente a mejorar los apoyos de otros elementos sobre ellos -forjados y cubiertas- para evitar que trabajen en la misma dirección de los movimientos naturales.

Desconfíamos seriamente de los procesos de recalce, y especialmente de los refuerzos de terrenos. Sólo en casos puntuales en que la cimentación ha sufrido daños o es claramente insuficiente, ambas cosas habitualmente por efecto de las distintas intervenciones o fases históricas de desarrollo del edificio, creemos que se justifica una intervención en el cimiento, pero siempre que ésta sea claramente controlada en su magnitud o cualidad y en la afección a la fábrica existente. Es decir, sólo si se trata de recalces puntuales del cimiento o de reparaciones constructivas del mismo y siempre que se delimite exactamente la forma, tamaño, resistencia, etc., de los elementos añadidos o de las modificaciones realizadas en lo existente. Por el contrario, creemos que los refuerzos en el terreno o los recalces en profundidad no son controlables en sí mismos ni en el efecto que pueden causar sobre el propio terreno ni sobre las estructuras de cimentación, por lo que en general los descartaremos como sistemas adecuados de reparación.

Por otro lado, la por lo general lenta evolución de los procesos de asiento y desplazamiento de los terrenos hace que el daño que se produce en las fábricas sea limitado y también de evolución lenta, lo que da márgenes muy grandes para una progresiva reparación constructiva, que adecúe su ritmo de intervención al del avance de los daños y que siempre esté mejorando la capacidad de la fábrica de sufrir nuevos daños. Se trata de evitar grandes consolidaciones y refuerzos globales, cuyo efecto sobre la fábrica puede ser demoledor, y sustituirlas por pequeñas reparaciones puntuales, tales como sellado de las grietas, recoloca- 
ción de elementos dislocados, inserción de injertos en zonas dañadas, siempre con elementos materialmente compatibles con los existentes, que en conjunto cumplen con dos criterios que creemos básicos de la restauración de edificios históricos: la compatibilidad de los materiales insertados con los existentes y la prosecución de los procesos históricos de reparación que podemos ver en todos ellos, como manera de manifestar la continuidad de nuestro trabajo con el que en otros momentos acometieron quienes tuvieron o sintieron la necesidad de conservar el edificio para sí mismos y para nosotros.

Y como último criterio, hay que establecer para todas las reparaciones propuestas un control y seguimiento posteriores, lo que se propone hacer de manera muy sencilla empleando a la propia iglesia como registro de sus problemas, como lo que ha venido siendo hasta ahora. Así, las reparaciones que se practiquen habrán de ser evidentes, dejando trazas claras del problema reparado para que en el futuro otros técnicos puedan reinterpretarlo y valorar la efectividad de la reparación. De este modo también pretendemos que nuestra intervención se integre dentro de ese proceso a medias histórico a medias natural en el que se encuentra la iglesia, sin cancelar su vida propia y sin pretender borrar de ella las huellas del paso del tiempo.

\section{Ficha técnica}

Obra: Restauración estructural de la iglesia de Santa Eulalia en Marquínez, Álava. Promoción: ARABARRI, S.A., Sociedad para la gestión del Patrimonio Cultural Edificado de Álava, Diputación Foral de Álava. Proyecto arquitectónico: Latorre y Cámara, S.L., arquitectos; Leandro Cámara y Pablo Latorre, autores; Rafael Martín e Isabel Antolín, arquitectos colaboradores; Esperanza Dúcar y Francisco Arroyo, dibujates; Diana Pardo, Mercedes Cortázar y Dolores Sanz, restauradoras; Luis Martínez Torres, geólogo. Análisis arqueológico: Grupo de Investigación en Arqueología de la Arquitectura de la Universidad del País Vasco, dirigido por Agustín Azkarate; Ismael García, coordinador del proyecto; Ismael García e Iban Sánchez, lectura de alzados; Iban Sánchez, José Cardoso y Daniel Vallo, excavación; Ismael García e Iban Sánchez, redacción de informe; Iban Sánchez y Sonia Gobbato, planos analíticos; Ondare Babesa, S.L., vaciado documental.

\section{Bibliografía}

Brebbia, Carlo (editor), 1989. Structural Repair and Maintenance of Historical Buildings, Basel-Boston-Berlin, Birkhäuser Verlag.

Brogiolo, Gian Pietro, 1995, Arqueología estratigráfica y restauración, en Informes de la Construcción, 46, 435, Madrid, Instituto E. Torroja, CSIC.

Brogiolo, Gian Pietro, 2002, Larcheologia delll'architettura in Italia nell'ultimo quinquennio (1997-2001), en Arqueología de la Arquitectura, 1, Vitoria, Universidad del País Vasco.

Caballero, Luis, 1995, Método para el análisis estratigráfico de construcciones históricas o "lectura de paramentos», en Informes de la Construcción, vol. 46, no 435, Madrid, Instituto E. Torroja, CSIC.

Caballero, Luis, 1996, El análisis estratigráfico de construcciones históricas, en El método arqueológico aplicado al proceso de estudio y de intervención en edificios históricos, Burgos, Junta de Castilla y León.

Cagnoni, G., 1996, La documentazione del degrado e del dissesto nell'analisi stratigrafica degli elevati, en Archeologia del'Architettura, 1, Firenze.

Carandini, Andrea, 1991, Storie dalla Terra. Manuale di scavo archeologico, Torino, Giulio Einaudi Editore.

Cámara, Leandro y Latorre, Pablo, 2002, Anamnesis de una estructura. en Arqueología de la Arquitectura, 1, Vitoria, Universidad del País Vasco.

Croci, Giorgio, 2001, Conservazione e restauro strutturale del beni architettonici, Torino, Utet Libreria.

Di Pasquale, Salvatore, 1996, L'arte del costruire. Tra conoscenza e scienza, Venezia, Marsilio Editore.

Di Stefano, Roberto, 1990, Il consolidamento strutturale, Napoli, Edizioni Scientifiche Italiane.

Doglioni, Francesco, 1997, Stratigrafia e restauro. Tra conoscenza e conservacione dell'architettura, Trieste.

García Gómez, Ismael, 2005, Santa Eulalia de Marquínez. Evolución históricoconstructiva, Vitoria, Arabarri.

Heymann, Jacques, 1969, The safety of masonry archs, primero publicado en International Journal of Mechanical Sciences; traducción al castellano en 1995, Teoria, historia y restauración de estructuras de fábrica, Madrid, Instituto Juan de Herrera.

Heymann, Jacques, 1999, El esqueleto de piedra, Madrid, Instituto Juan de Herrera. Original inglés, 1995, The Stone Skeleton, Cambridge University Press.

Huerta, Santiago, 2004, Arcos, bóvedas y cúpulas. Geometría y equilibrio en el cálculo tradicional de estructuras de fábrica, Madrid, Instituto Juan de Herrera.

Icomos-Iscarsah, 2001, Recommendations For The Analysis, Conservation And Structural Restoration Of Architectural Heritage.

Lemaire, R.M., Van Balen, K. (editores), 1988, Stable-Unstable. Structural Consolidation of Ancient Buildings, Lovaina, Leuwen University Press.

Mileto, Camilla y Vegas, Fernando, 2004, El análisis estratigráfico constructivo y el proyecto de restauración arquitectónica, Arqueología de la Arquitectura, 3, Vitoria, Universidad del País Vasco.

Mastrodicasa, Sisto, 1988, Dissesti statici delle strutture edilizie, Milano, Ulrico Hoepli Editore.

Roca, P., González, J.L., Oñate, E. y Lourenço, P.B. (editores), 1998, Structural analysis of historical constructions II. Possibilities of numerical and experimental techniques, Barcelona, CIMNE.

Timoshenko, Stephen, 1983, History of Strength of Materials. Nueva York, Dover Publications Inc. (ed. orig. 1953).

Recibido: 7 de junio de 2010 Aceptado: 18 de octubre de 2010 